Review

\title{
Cellular immunotherapy in multiple myeloma: Lessons from preclinical models
}

\author{
M. Binsfeld ${ }^{\mathrm{a}}$, K. Fostier ${ }^{\text {b }}$, J. Muller ${ }^{\text {a }}$, F. Baron ${ }^{\mathrm{a}, \mathrm{c}}$, R. Schots ${ }^{\mathrm{b}}$, Y. Beguin ${ }^{\mathrm{a}, \mathrm{c}}$, R. Heusschen ${ }^{\mathrm{a}, *, 1}$, J. Caers ${ }^{\mathrm{a}, \mathrm{c}, 1}$ \\ a Laboratory of Hematology, GIGA-Research, University of Liège, Avenue de l'Hôpital 1, 4000 Liège, Belgium \\ ${ }^{\mathrm{b}}$ Department of Clinical Hematology, Universitair Ziekenhuis Brussel (UZ Brussel), Brussels, Belgium \\ c Department of Medicine, Division of Hematology, University and CHU of Liège, Liège, Belgium
}

\section{A R T I C L E I N F O}

\section{Article history:}

Received 12 May 2014

Received in revised form 31 July 2014

Accepted 2 August 2014

Available online 7 August 2014

\section{Keywords:}

Multiple myeloma

Mouse models

Immunotherapy

Transplantation

Adoptive transfer

Vaccination

\section{A B S T R A C T}

The majority of multiple myeloma patients relapse with the current treatment strategies, raising the need for alternative therapeutic approaches. Cellular immunotherapy is a rapidly evolving field and currently being translated into clinical trials with encouraging results in several cancer types, including multiple myeloma. Murine multiple myeloma models are of critical importance for the development and refinement of cellular immunotherapy. In this review, we summarize the immune cell changes that occur in multiple myeloma patients and we discuss the cell-based immunotherapies that have been tested in multiple myeloma, with a focus on murine models.

(C) 2014 Elsevier B.V. All rights reserved.

\section{Contents}

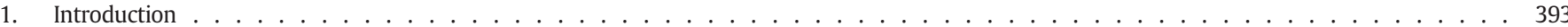

2. Immune cell alterations in multiple myeloma . . . . . . . . . . . . . . . . . . . . . . . . . . . . . . . . . 393

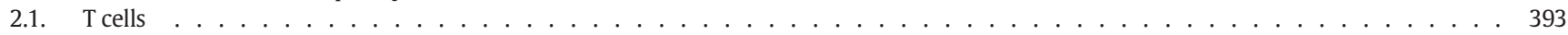

2.2. B cells and humoral immunity . . . . . . . . . . . . . . . . . . . . . . . . . . . . . . . . .

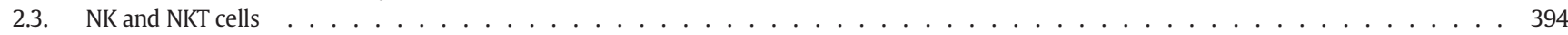

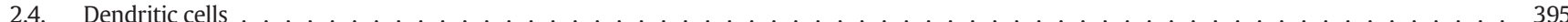

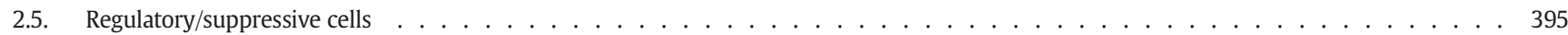

3. Transplantation-based immunotherapy in multiple myeloma . . . . . . . . . . . . . . . . . . . . . . . . . . . . . . 395

3.1. Allogeneic transplantation in MM patients . . . . . . . . . . . . . . . . . . . . . . . . . . . . 395

3.2. Allogeneic transplantation in immunocompetent murine MM models . . . . . . . . . . . . . . . . . . . . . . . . . . . 396

3.3. Xenogeneic transplantation in immunodeficient murine MM models . . . . . . . . . . . . . . . . . . . . . . . . . . . . . . 396

4. Adoptive cell transfer in multiple myeloma . . . . . . . . . . . . . . . . . . . . . . . . . . . . . . . . . . . . 397

4.1. Adoptive T-cell transfer . . . . . . . . . . . . . . . . . . . . . . . . . . . . . . . . . . . . . 397

4.2. Adoptive NK-cell transfer . . . . . . . . . . . . . . . . . . . . . . . . . . . . . . . . 398

4.3. Adoptive chimeric antigen receptor T \& NK-cell transfer . . . . . . . . . . . . . . . . . . . . . . . . . 398

$5 . \quad$ Dendritic cell vaccination . . . . . . . . . . . . . . . . . . . . . . . . . . . . . . . . . . . . 399

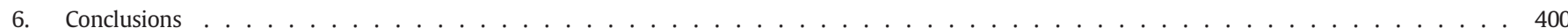

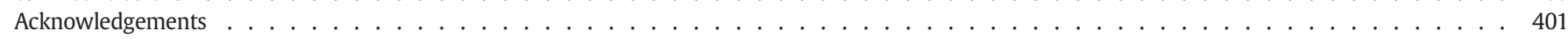

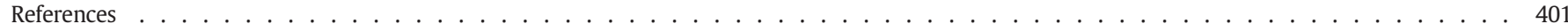

\footnotetext{
* Corresponding author. Tel.: +3243664915.

E-mail address: r.heusschen@ulg.ac.be (R. Heusschen).

$1 \mathrm{RH}$ and JC are co-senior authors.
} 


\section{Introduction}

Multiple myeloma (MM) is a clonal B-cell malignancy characterized by an accumulation of malignant plasma cells in the bone marrow, and the presence of a monoclonal protein in the serum and/or urine, decreased normal immunoglobulin levels and lytic bone disease [1]. Standard treatment of MM in patients up to the age of 65 years consists in an initial induction based on the administration of immunomodulatory agents (thalidomide or lenalidomide) or the proteasome inhibitor bortezomib, combined with chemotherapy or dexamethasone, followed by autologous stem cell transplantation (auto-SCT) and consolidation/ maintenance therapy. Elderly patients benefit from combination therapy including novel agents, followed by prolonged maintenance therapy until disease progression. However, despite improvement of results with current drug therapies, the vast majority of patients relapse due to the appearance or persistence of multidrug-resistant plasma cell clones.

Immunotherapy is a promising field in cancer research and includes both non-cellular immunotherapy and cell-based immunotherapy. Different forms of cellular immunotherapy with potent anti-myeloma activity have been investigated and validated in pre-clinical in vitro and in vivo models. In fact, immunotherapy as a novel treatment modality might offer long-term disease control in MM patients. However, numerous challenges have to be addressed before immunotherapy can be broadly used to treat MM patients, such as the identification of an optimal target antigen for vaccination strategies, the occurrence of myeloma resistance and the general immunosuppressive nature of multiple myeloma which hampers immune cell-based treatment approaches. Thus, addressing these challenges in murine models is of great interest.

Several immunocompetent murine models of MM have been established and have been of value for the preclinical investigation of MM immunotherapy (Table 1). MOPC315 and similar cell lines (J558, HOPC, ...) are plasmacytoma-resembling transplantable myeloma cells that were isolated from granulomas obtained after injecting mineral oil in the peritoneum of Balb/c mice [2]. The 5TMM model comprises the transplantable 5T2MM and 5T33MM cell lines and the 5TGM1 subclone $[3,4]$. This model originates from aging C57BL/KaLwRij mice, an inbred substrain of $\mathrm{C} 57$ black mice, in which a small proportion of the animals spontaneously develop a myeloma-like disease with a primary localization of myeloma cells in the bone marrow, resulting in anemia and bone lesions, closely resembling the human counterpart. Conversely, immunodeficient models have been developed to assess the effectiveness of cellular immunotherapy in xenograft models of human MM (Table 2). There is currently no ideal myeloma model that accurately reflects all aspects of the disease and each model has its advantages and limitations. Therefore, it is important that investigators chose adequate models for answering their questions.

In this review, we first summarize the general immune alterations observed in multiple myeloma. We provide an overview of the different cellular immunotherapeutic strategies that have been tested in murine MM models, i.e. transplantation-based and adoptive transfer-based immunotherapy and dendritic cell vaccination, and describe how immune cells may be manipulated to overcome the MM-related immune suppressive effects in order to eradicate the malignant clone. Relevant findings from in vitro studies as well as clinical studies are also discussed.

\section{Immune cell alterations in multiple myeloma}

Impairment of the immune system is a well-known phenomenon associated with MM. It is involved in MM progression and responsible for an increased risk of infections and secondary malignancies in myeloma patients. On the one hand, this immune alteration is caused by the suppression of normal hematopoiesis through replacement of the normal bone marrow by malignant plasma cells. However, suppression of normal hematopoiesis can also occur at a relatively low MM infiltration rate due to MM-related microenvironmental changes that impair the proliferation and function of the $\mathrm{CD} 34^{+}$hematopoietic stem and progenitor cells [5].

Moreover, the immune system is actively suppressed by myeloma cells and through their interaction with the microenvironment. This immune suppression is related to several mechanisms including secretion of immunosuppressive factors and recruitment of immune suppressive cells by MM cells, deficient antigen processing and presentation by host antigen-presenting cells and inhibition of activated $\mathrm{T}$ cells via expression of co-inhibitory molecules by the malignant cells [6]. Both the number and the activity of several immune effector cells (Fig. 1) are affected by immune suppression in MM and this partially explains the anti-neoplastic activity of non-cellular immunotherapies, such as immunomodulatory drugs, which are able to revert immune effectors to their physiological functions [7-12].

\section{1. $T$ cells}

T lymphocytes, i.e. CD4 helper T cells and CD8 cytotoxic T cells (CTLs), play a crucial role in anti-tumor immunity. In myeloma patients, several CD4 and CD8 T-cell abnormalities have been described, most frequently a decrease of CD4 T cells [13-18]. Specifically, Schutt et al. reported reduced levels of memory CD4 $\mathrm{T}$ cells $\left(\mathrm{CD} 4^{+} \mathrm{CD} 45 \mathrm{RO}^{+}\right)$, as well as activated $\mathrm{CD}^{+}{ }^{+} \mathrm{HLA}-\mathrm{DR}^{+} \mathrm{T}$ cells in the blood of MM patients [18]. The decrease in total CD4 T cells was associated with a reduced survival, an advanced disease stage and an increased relapse probability $[15,16]$. In addition, viral antigen-specific CTL response is impaired in MM patients, which might partially explain the limited success of anti-myeloma immunizations [19].

Within the CD4 subset, different T helper (Th) subsets can be distinguished based on the secretion of distinct cytokine profiles. Th1 and Th2 cells cross-regulate each other's development, and the balance between these cell types is important for an efficient immune response. Th1 cells produce interferon (IFN)- $\gamma$ and interleukin (IL)-2 and play a role in cellmediated immunity, while Th2 cells promote humoral immunity and produce IL-4, IL-5, IL-6, IL-10, IL-13 and IL-25 [20,21]. In myeloma patients, abnormal Th1/Th2 ratios have been reported [17,20,22]. Sharma et al. describe a polarization towards Th2 cytokines along with Th1 suppression [22] while others report a decrease of Th2 cells, leading to an increased Th1/Th2 ratio [17]. The observations of Sharma et al. are supported by findings in a murine MM model in which anti-myeloma activity of Th1 cells was reported [23], and by observations suggesting an attenuation of Th1 responses induced by MM cells [24]. However, additional studies are needed to confirm these findings.

Th17 cells, an IL-17 secreting subset of CD4 T cells, could also play an important role in MM. The MM-secreted cytokines transforming growth factor (TGF)- $\beta$ and IL- 6 induce the differentiation of Th17. Subsequently, IL-17 promotes MM cell growth, resulting in a positive feedback loop [25]. Indeed, increased proportions of Th17 cells have been observed in blood and bone marrow from MM patients. This increase could also be triggered by dendritic cells [26,27].

Several of these T-cell alterations might occur due to the excessive production of TGF- $\beta$ by MM cells, which suppresses T-cell responses through the inhibition of the IL-2 autocrine pathway in these cells [8, 28]. In addition, Gorgun et al. demonstrated that MM cells induce the expression of the suppressor of cytokine signaling (SOCS) 1 in CD4 and CD8 $\mathrm{T}$ cells, which is a negative regulator of IL-2, IFN- $\gamma$ and IL- 6 signaling, thus attenuating Th1 and CTL responses $[12,24]$.

Another T-cell suppressive mechanism involves the programmed death 1 (PD-1) coinhibitory molecule, a transmembrane protein expressed on activated $\mathrm{T}$ cells that is involved in T-cell homeostasis. Binding of PD-1 to its ligand PD-L1 (B7-H1) generates an inhibitory signal, resulting in a reduction of T-cell proliferation and production of cytokines, which counterbalances T-cell stimulatory signals [29]. In contrast to normal plasmocytes, myeloma cells express PD-L1 [29-31] and T cells from MM patients express increased levels of PD-1 [30]. 
Tamura et al. showed that bone marrow stromal cells are responsible for PD-L1 up-regulation on MM cells through IL-6 secretion. The presence of PD-L1 on myeloma cells induces T-cell apoptosis and anergy of tumor-specific CTLs in vitro, confirming the importance of the PD-1/ PD-L1 axis in the impairment of anti-myeloma T-cell response. In addition, PD-L1 directly promotes myeloma progression, as PD-L1+ myeloma cells display an increased proliferation rate and resistance to chemotherapy compared to PD-L1 ${ }^{-}$myeloma cells. In accordance with these in vitro observations, high levels of PD-L1 on myeloma cells in patients are associated with an increased myeloma infiltration in their bone marrow and signs of clinical progression [32].

Regarding the repertoire of T-cell receptor (TCR) rearrangements in MM patients, oligoclonal expansions within CD4 T cells and CTLs have been described [33-35]. These expansions are likely generated through a persistent stimulation by tumor-associated antigens, but their clinical significance is not yet clear. Further studies to elucidate the specificity and responsiveness of these clones are of great interest for immunotherapy, for example idiotype (Id)-targeted vaccination. In fact, Idspecific T cells are present in MM patients, but their role in antimyeloma immune response remains to be determined [36]. Interestingly, a peripheral deletion of Id-specific CD4 T cells and functional T-cell unresponsiveness were demonstrated in a murine plasmacytoma model using TCR transgenic mice [37].

\subsection{B cells and humoral immunity}

A decrease in $\mathrm{CD} 19^{+} \mathrm{B}$ cells has also been reported in MM patients $[18,38,39]$ and B-cell levels were inversely correlated with disease stage [39]. Indeed, humoral immune deficiency with reduced levels of polyclonal immunoglobulins is a well-known phenomenon in myeloma $[10,18]$ and is caused by both a decreased number of B cells, and by functional defects in B cells in MM, such as a reduced ability to secrete immunoglobulins and to differentiate into antibody-secreting plasma cells [38] and a reduced up-regulation of CD80 costimulatory receptor expression in response to stimulation [40]. The production of TGF- $\beta$ by myeloma and stromal cells contributes to the inhibitory effects on normal B-cell proliferation and antibody secretion [41].

\subsection{NK and NKT cells}

Natural killer (NK) cells mediate the lysis of cells that express decreased major histocompatibility complex class I (MHC I) levels, like virally infected or tumor cells. They express killing activating receptors, such as natural cytotoxicity receptors (NCRs) and NKG2D, and killing inhibitory receptors (KIRs). The MHC I-like molecules MICA and MICB (MHC I Chain-related protein A and B) are ligands for NKG2D activating receptor. NK cell-mediated lysis is suppressed as long as inhibitory signals are dominant through the binding of KIRs to their ligands on target cells, such as MHC I. However, when MHC I is absent/downregulated, a strategy frequently used by tumor cells in order to evade lysis by CTLs, activating signals on NK cells become dominant and target cells are lysed [12,42].

Bone marrow-derived MM cells in early-stage disease are sensitive to NK-cell lysis because of their low MHC I and high MICA levels. In contrast, late-stage MM cells have a high MHC I and a low MICA expression, suggesting the emergence of NK-resistant subclones during disease progression [42]. These results are in accordance with reports describing an increase of NK-associated activation markers in early stage MM [43] and reduced NK-cell levels in untreated MM [18].

Fauriat et al. described that NK cells from MM patients express normal levels of NCRs and NKG2D. In contrast, the expression of 2B4/CD244 coreceptor and CD16 (Fc-receptor) is reduced. Since MM cells express CD48, a ligand for $2 B 4 / C D 244$, the down-regulation of $2 B 4 / C D 244$ on NK cells might be another immune escape mechanism of myeloma cells. The decrease of CD16, an important mediator of the antibodydependent cell-mediated cytotoxicity (ADCC) function of NK cells, could be due to continuous exposure to monoclonal immunoglobulins in MM patients [44]. Moreover, NK cells from MM patients express PD-1, whereas normal NK cells do not. Thus, expression of PD-L1 on MM cells could decrease the NK-cell response against myeloma. This was confirmed by neutralization of the PD-1/PD-L1 axis with an antiPD-1 antibody, which resulted in enhanced anti-myeloma NK-cell function in vitro. Interestingly, lenalidomide down-regulates PD-L1 on MM cells and could act synergistically with the anti-PD-1 antibody [31]. Altogether, these findings underscore the interest of enhancing the

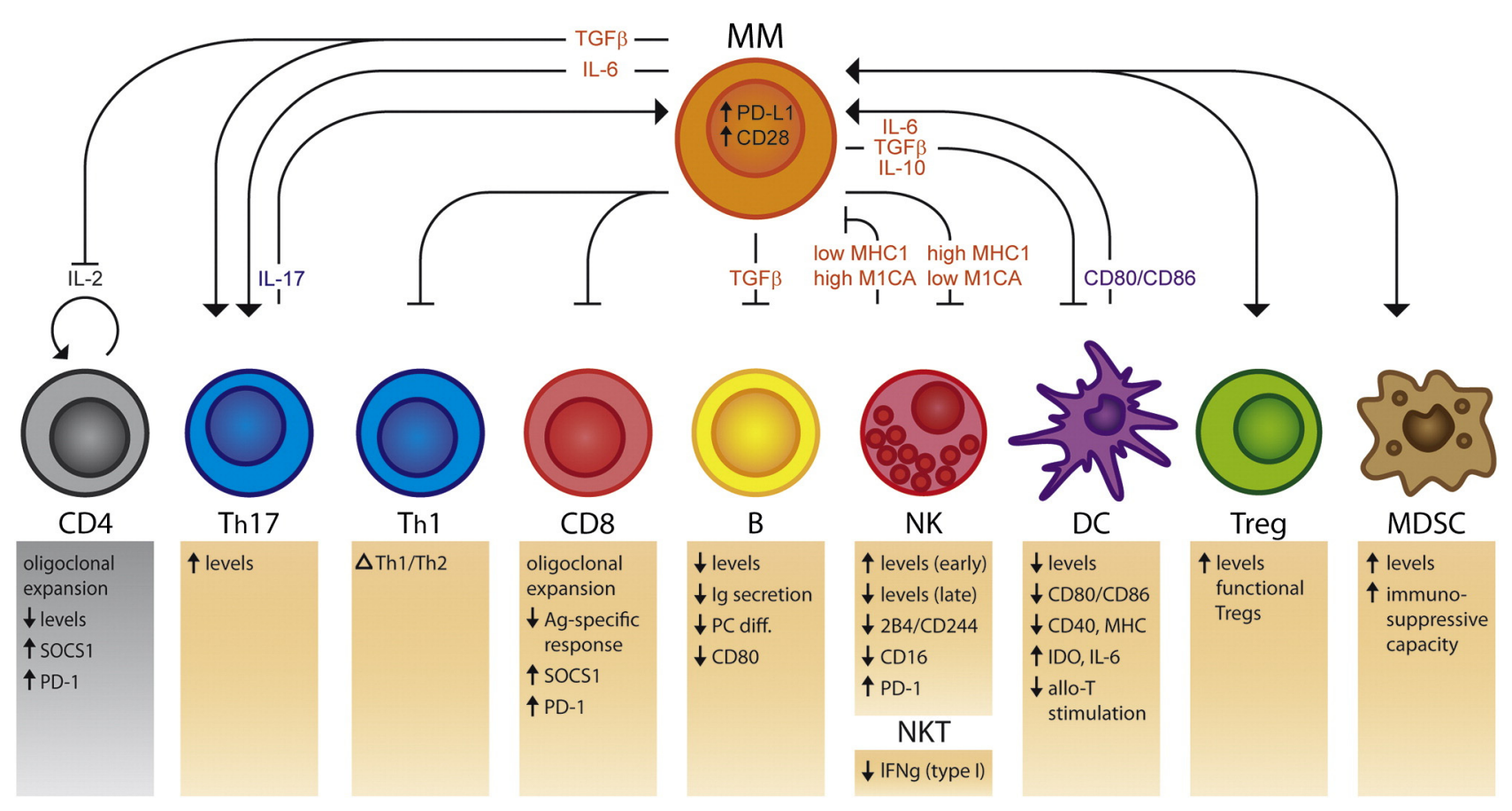

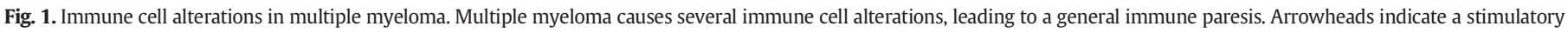

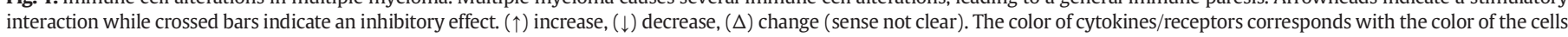
of their origin. 
sensitivity of MM cells to NK-cell lysis or the capacity of NK cells to induce myeloma cell lysis, and identify PD-1 as an interesting immunotherapeutic target on NK cells.

NKT cells are CD1d-restricted T cells which also display NK characteristics. Different subtypes have been described: type I or invariant NKT $\left(\mathrm{V} \alpha 24^{+} \beta 11^{+}\right)$and type II NKT cells $\left(\mathrm{V} \alpha 24^{-} \beta 11^{-}\right)$. In patients with progressive myeloma disease, type I NKT cells are functionally defective due to a reduced ligand-dependent IFN- $\gamma$ production [45]. In addition, a distinct type II NKT population that binds to inflammationassociated lysophospholipids present in the plasma of MM patients has been identified [46].

\subsection{Dendritic cells}

Several reports describe numerical changes and diverse functional defects of dendritic cells (DCs) in MM. Both myeloid and plasmacytoid DCs and their precursors are decreased in MM patients [47-50]. In a first study, Brown et al. reported that tumor-derived TGF- $\beta 1$ and IL-10 inhibit the up-regulation of CD80 and CD86 co-stimulatory molecules on DCs from MM patients [40]. Next, they confirmed an impaired ability to up-regulate CD80 in DCs from stage I and III myeloma patients. Both IL12 and IFN- $\gamma$ were able to neutralize this defect in CD80 up-regulation [48]. Interestingly, the CD80/CD86-ligand CD28 is overexpressed on MM cell surface during disease progression, and its engagement to CD80/CD86 on stromal DCs directly transduces a pro-survival signal to the myeloma cell, while simultaneously inducing the production of IL-6 and the immunosuppressive enzyme indoleamine 2,3-dioxygenase (IDO) by DCs [51].

Other functional defects that were described in DCs from MM patients include a reduced CD40 and CD80 expression, reduced MHC expression levels, and a decreased capacity to stimulate allogeneic Tcell proliferation and cytokine production by these cells [47,52]. These functional defects are partially due to an IL-6-mediated inhibition of DC development [47]. Moreover, loading of MM tumor antigens has been shown to cause functional defects in DCs, which can be overcome by vascular endothelial growth factor (VEGF) neutralization [53]. Similar observations were made in the murine 5TGM1 MM model in which an inhibition of DC differentiation and function by MM cells via IL-6, IL10 , and TGF- $\beta$ and activation of p38 mitogen-activated protein kinase (MAPK) signaling have been reported [54]. This inhibitory mechanism was confirmed in monocyte-derived DCs from myeloma patients and p38 inhibition resulted in a restoration of DC function [55]. Restoring or ensuring normal DC function might be of great interest for several cellular immunotherapy approaches that depend on it.

\subsection{Regulatory/suppressive cells}

Regulatory T cells (Tregs) are characterized by a CD ${ }^{+} \mathrm{CD} 25^{+} \mathrm{Foxp}^{+}$ phenotype and play an essential role in the prevention of autoimmunity and the regulation of immune responses. They exert their suppressive function through cell-to-cell contact or secretion of immunosuppressive cytokines like TGF- $\beta$ and IL-10 [56]. Initially, a decrease in Treg numbers was reported in MM patients, along with a defect in their ability to suppress T-cell proliferation [57]. In contrast, several more recent studies have concluded that the number of functionally intact Treg is increased in MM patients [49,50,58-60]. These observations are in accordance with observations made in several other malignancies [56], and suggest that MM cells evade immune surveillance partially through the increase of suppressive Tregs [60]. The myeloma-promoting role of Tregs is reinforced by observations in MM patients showing a shorter survival for patients with high Treg percentages [50] and indicating that the number of Tregs is a predictive marker for the risk of disease progression [60]. The finding that MM cells are able to induce the generation of Tregs in vitro further corroborates these results [61]. Furthermore, Tregs have been shown to expand and accumulate in the bone marrow of MM patients after allogeneic stem cell transplantation, and Tregs found in these patients are endowed with a strong inhibitory function, potentially inhibiting anti-myeloma immune control after transplantation [62].

Myeloid-derived suppressor cells (MDSCs) are a heterogeneous population of immature myeloid cells with immune suppressive properties. MDSCs have been shown to accumulate in cancer patients, through tumor- and stromal-secreted pro-inflammatory mediators, and are able to facilitate tumor growth by hampering anti-tumor immunity. Although their phenotype in humans is not yet well-defined, they are generally delineated as $\mathrm{CD} 11 \mathrm{~b}^{+} \mathrm{CD}_{3} 3^{+} \mathrm{HLA}-\mathrm{DR}^{-}$and comprise monocytic and granulocytic/neutrophil-like subpopulations [63]. An increase of MDSCs in peripheral blood and bone marrow of MM patients has been observed $[49,64,65]$. Moreover, MDSCs induce MM growth and suppress T-cell mediated immune responses, while MM cells induce MDSC development, resulting in a bidirectional interaction [64]. In murine models, myeloma disease enhances the immunosuppressive capacity of MDSC in the bone marrow [66], and MDSCs play a critical role in MM progression at early stages of disease [65]. Interestingly, it has been shown that MDSCs are able to induce Treg differentiation in vitro, although it is not clear at this point whether this occurs in MM [67]. Furthermore, the specific contribution of MDSC subsets to MM progression is not well understood. Thus, overcoming or circumventing the immunosuppressive environment mediated by Tregs and MDSCs is an important challenge for cell-based immunotherapy.

\section{Transplantation-based immunotherapy in multiple myeloma}

\subsection{Allogeneic transplantation in MM patients}

Allogeneic stem cell transplantation (allo-SCT) is an active form of immunotherapy used in numerous hematological malignancies. This strategy presents a multifold interest. First, malignant cells are eradicated through a myeloablative conditioning treatment using high-dose irradiation and/or chemotherapeutic drugs. Next, patients receive an alloSCT to rescue the patient after myeloablative conditioning. Moreover, as an advantage compared to auto-SCT, donor immune cells in allo-SCT are able to recognize and eradicate the potential residual malignant cells after transplantation, a characteristic known as graft-versus-tumor effect. Of note, reduced-intensity conditioning regimens (RIC) have recently been introduced, which allow transplantation in patients that are considered too high risk for myeloablative conditioning.

In MM patients there is evidence of a graft-versus-myeloma (GvM) effect. Donor lymphocyte infusions (DLIs) are capable of inducing a complete response in relapsed patients [68] and the association of chronic graft-versus-host disease (GvHD) with a reduced relapse rate after transplantation further supports the existence of a GvM effect $[69,70]$. In addition, it has been shown that long-term disease control can be achieved in a subset of MM patients after allo-SCT [71]. However, important challenges remain, as allo-SCT in MM is still associated with a relatively high relapse rate that could be explained by the immune suppressive phenotype of residual MM cells [8]. Moreover, the use of allo-SCT in MM also represents a certain risk of GvHD and transplantrelated mortality, despite the use of RIC regimens. Several studies, including phase III multicenter studies, compared auto-SCT followed by RIC allo-SCT (auto-allo-SCT) to a tandem auto-SCT approach [70, 72-78]. Auto-allo-SCT was not superior to tandem auto-SCT in patients with high-risk de novo MM [72] or in patients with standard-risk disease [70]. In newly diagnosed MM, despite encouraging progressionfree survival in auto-allo-SCT arm, this regimen was associated with high morbidity and mortality and thus not beneficial compared to tandem auto-SCT [74]. Another study showed, in contrast, an overall benefit for auto-allo-SCT arm in newly diagnosed MM with superior survival [73]. Moreover, long-term outcome was better in patients that received auto-allo-SCT rather than tandem auto-SCT $[75,77]$. Finally, in patients that relapsed after the first auto-SCT, controversial results have been shown regarding the feasibility of allo-SCT as salvage therapy compared 
Table 1

Cellular immunotherapy in immunocompetent murine myeloma models.

\begin{tabular}{|c|c|c|c|c|c|}
\hline \multicolumn{4}{|l|}{ MM model } & \multicolumn{2}{|l|}{ Cellular immunotherapy } \\
\hline $\begin{array}{l}\text { Murine cell } \\
\text { line }\end{array}$ & Origin & In vivo growth & Type & Anti-myeloma effect? & Ref \\
\hline \multicolumn{6}{|c|}{ 5TMM in C57Bl/KalwRij mice } \\
\hline 5T2MM & Spontaneous MM & BM tropism & Adoptive transfer (Tregs) & No (increased MM progression) & [87] \\
\hline \multirow[t]{3}{*}{ 5T33MM } & Spontaneous MM & BM tropism & AlloSCT/DLI (C3.SW-H2 $/$ Snj donor) & Yes (extended with DC-vaccinated donor) & {$[82]$} \\
\hline & & & $\begin{array}{l}\text { Adoptive transfer (chNKG2D-expressing } \\
\text { T cells) }\end{array}$ & Yes + protective immune response & {$[88]$} \\
\hline & & & $\begin{array}{l}\text { Adoptive transfer (NK cells) }+ \text { systemic } \\
\text { IL-2 treatment }\end{array}$ & Yes & [96] \\
\hline \multirow[t]{2}{*}{ 5TGM1 } & $\mathrm{m}$ & BM tropism & Adoptive transfer (Id-specific CTL or Th1) & Yes & {$[23]$} \\
\hline & & & $\begin{array}{l}\text { DC vaccination (Id-KLH-pulsed or } \\
\text { tumor-lysate-pulsed) }\end{array}$ & Yes + protective immune response & {$[138,141]$} \\
\hline \multicolumn{6}{|c|}{ Mineral oil-induced plasmacytoma in Balb/c mice } \\
\hline \multirow[t]{2}{*}{ HOPC-1F } & Induced plasmacytoma & Extramedullar & Allo-SCT (DBA/2 donor) & Yes (only with Id-vaccinated donor) & {$[81]$} \\
\hline & & plasmacytoma & Auto-SCT + Id-pulsed DC vaccination & Yes & [129] \\
\hline $\mathrm{J} 558$ & Induced plasmacytoma & $\begin{array}{l}\text { Extramedullar } \\
\text { plasmacytoma }\end{array}$ & $\begin{array}{l}\text { Prophylactic fusion vaccine } \\
\text { (mature DC/Il-4-secreting J558) }\end{array}$ & Yes + protective immune response & [140] \\
\hline \multirow[t]{2}{*}{ J558L } & J558 without H-chain & Extramedullar & DC vaccination (Id-KLH-loaded) & No & [137] \\
\hline & & plasmacytoma & DC vaccination (myeloma cell-loaded) & Yes & [137] \\
\hline \multirow[t]{2}{*}{$\mathrm{SP} 2 / 0$} & $\begin{array}{l}\text { Fusion of splenocytes with } \\
\text { plasmacytoma-derived cell line }\end{array}$ & $\begin{array}{l}\text { Extramedullar } \\
\text { plasmacytoma }\end{array}$ & $\begin{array}{l}\text { Adoptive transfer ( } \mathrm{T} \text { cells) }+ \\
\text { intra-tumoral gene transfer }\end{array}$ & Yes (synergistic) & {$[90,91]$} \\
\hline & & & $\begin{array}{l}\text { Adoptive transfer (tumor } \\
\text { antigen-specific lymphocytes) }\end{array}$ & Yes + protective immune response & {$[94]$} \\
\hline \multirow[t]{2}{*}{ VKCK } & SP2/0Ag14 cells expressing chimeric & Extramedullar & Adoptive transfer ( $\mathrm{T}$ cells or $\mathrm{CTL}$ ) & Yes & [92] \\
\hline & light chain of ccM4 antibody & plasmacytoma & $\begin{array}{l}\text { Adoptive transfer (CD4 T cells from } \\
\text { VKCK- } \gamma \text { I/II-vaccinated mice) }\end{array}$ & $\begin{array}{l}\text { Yes }+ \text { protective immune response from } \\
\text { VKCK- } \gamma(\mathrm{I} / \mathrm{II}) \text { vaccination }\end{array}$ & [93] \\
\hline MOPC315.4 & Induced plasmacytoma & $\begin{array}{l}\text { Extramedullar } \\
\text { plasmacytoma }\end{array}$ & $\begin{array}{l}\text { Adoptive transfer (Id-specific T cells from } \\
\text { TCR-transgenic donors) }\end{array}$ & Yes (dependent on CD4 T cells) & {$[89]$} \\
\hline
\end{tabular}

to auto-SCT $[76,78]$. Altogether, these findings explain why allo-SCT remains a controversial therapy for MM.

In order to improve the results of allo-SCT in MM, the use of immunomodulatory agents after transplantation could be of interest in order to increase the GvM effect and/or to decrease the severity of GvHD. However, caution is warranted, as the use of lenalidomide as maintenance therapy after allo-SCT might be associated with an unacceptable risk of GvHD [79]. In contrast, the use of bortezomib after RIC allo-SCT in combination with DLI seems to be feasible [80]. Thus, given the controversial status of allo-SCT in MM and the potential risk associated with the use of immunomodulatory agents in an attempt to modulate the balance between GvM and GvHD, further studies are required. Murine models are of great interest for this because they permit specific study of the GvM versus GvHD reactivity and allow for testing new therapeutic strategies prior to human trials.

\subsection{Allogeneic transplantation in immunocompetent murine MM models}

The first murine MM model in which allo-SCT-based immunotherapy was tested consisted in Balb/c mice $\left(\mathrm{H}-2^{\mathrm{d}}\right)$ injected intraperitoneally with HOPC-1F MM cells. Two days later, these mice were lethally irradiated and transplanted with cells from MHC-matched $\left(\mathrm{H}-2^{\mathrm{d}}\right)$ DBA/2 donors [81]. In this model, mice transplanted with unmanipulated bone marrow cells could not achieve long-term disease-free survival (>180 days). Only a moderate GvM effect was observed after coadministration of splenocytes, with $8 \%$ of mice achieving long-term survival. In contrast, bone marrow grafts derived from Id-protein vaccinated donor mice resulted in a significant GvM response, with $63 \%$ of mice achieving long-term disease-free survival, which was further increased when splenocytes from the same donor were co-administrated. Interestingly, donor Id-vaccination did not increase the incidence of severe acute GvHD in recipient mice. Finally, in vitro data suggested that allogeneic Id-specific CD8 T cells were implicated in the GvM response, as these cells mediated specific lysis of HOPC- $1 \mathrm{~F}$ cells. Thus, donor immunization can induce strong GvM effects after allo-SCT in the Balb/c HOPC-1F model. However, this model poorly resembles human MM disease, as myeloma cells are injected intraperitoneally and give rise to abdominal tumors.

Next, a murine MM allo-SCT model was established in which C57Bl/ KaLwRij.Hsd $\left(\mathrm{H}-2^{\mathrm{b}}\right)$ recipient mice received irradiation followed by allo-SCT from MHC-matched C3.SW-H2 ${ }^{\mathrm{b}} / \mathrm{SnJ}$ donors. After an immune reconstitution period of two months, recipients were inoculated with the 5T33MM murine cell line and developed myeloma disease. Posttransplantation immunotherapy using DLI prolonged the median survival of diseased mice. Additional DC vaccination of the DLI-recipient mice, using DC loaded with the $\mathrm{H} 7$ minor histocompatibility antigen that differs between donor and recipient strains, further extended survival without inducing GvHD by targeting the H7-presenting MM cells. Percentages of effector memory CD8 T cells were increased in the bone marrow of transplanted MM mice, irrespective of posttransplantation treatment. Furthermore, both MM growth and posttransplantation immunotherapy (DLI plus DC vaccination) caused a decrease of the homeostatic bone marrow-homing chemokine stromal cell-derived factor 1 (SDF1/CXCL12) levels and a strong induction of inflammatory chemokine expression in the bone marrow of recipient mice along with an increased expression of inflammatory homing receptors on donor $\mathrm{T}$ cells. This promoted an inflammation-driven migration of T cells towards the bone marrow, possibly contributing to a more effective GvM response [82].

So far, no studies have been reported in which allo-SCT was used after the establishment of MM in immunocompetent murine models that resemble human disease more closely, i.e. displaying bone marrow tropism.

\subsection{Xenogeneic transplantation in immunodeficient murine MM models}

A xenograft model was developed by Rozemuller et al. by engrafting GFP/luciferase-transfected human MM cell lines into immunodeficient RAG2 $2^{-/-} \gamma \mathrm{c}^{-/-}$mice. This model allows bioluminescence imaging of MM development, and myeloma cells preferentially infiltrate the bone marrow as in human disease. After infusion of myeloma-bearing mice with high doses of allogeneic human peripheral blood mononuclear 
Table 2

Cellular immunotherapy in immunodeficient murine xenograft models with human myeloma cells.

\begin{tabular}{|c|c|c|c|c|c|}
\hline \multicolumn{3}{|l|}{ MM model } & \multicolumn{3}{|l|}{ Cellular immunotherapy } \\
\hline Human myeloma cells & $\begin{array}{l}\text { Immunodeficient } \\
\text { recipient mice }\end{array}$ & In vivo growth & Type & Anti-myeloma effect? & Ref \\
\hline U266 & $\mathrm{RAG}^{-1-} \gamma \mathrm{c}^{-/-}$ & BM tropism & $\begin{array}{l}\text { Allo-transplantation } \\
\text { (human PBMC) }\end{array}$ & Yes & [83] \\
\hline RPMI-8226/S & $\mathrm{RAG}^{-/-} \gamma \mathrm{c}^{-/-}$ & BM tropism & $\begin{array}{l}\text { Allo-transplantation } \\
\text { (human PBMC) }\end{array}$ & Poor GvM response & [83] \\
\hline \multirow[t]{3}{*}{ RPMI-8226 } & CD122-depleted NOD/SCID & BM tropism & Human naive T-cell transfer & Yes & {$[84]$} \\
\hline & NSG & SC plasmacytoma & $\begin{array}{l}\text { Adoptive transfer } \\
\text { (anti-BCMA CAR T cells) }\end{array}$ & Yes & [115] \\
\hline & NOD/SCID & SC plasmacytoma & $\begin{array}{l}\text { Adoptive transfer } \\
\text { (anti-Lewis CAR T cells) }\end{array}$ & Yes & [116] \\
\hline \multirow[t]{2}{*}{ U266 or RPMI-8226 or LME- 1} & $\mathrm{RAG}^{-1-} \gamma \mathrm{c}^{-/-}$ & Diverse & $\begin{array}{l}\text { Allo-transplantation } \\
\text { (human PBMC) }\end{array}$ & $\begin{array}{l}\text { Yes, but variable (depending on } \\
\text { MM immunogenicity) }\end{array}$ & [85] \\
\hline & & & $\begin{array}{l}\text { PBMC transplantation }+ \\
\text { Treg coinfusion }\end{array}$ & $\begin{array}{l}\text { Impairment of GvM response } \\
\text { for extramedullar myeloma, } \\
\text { but not for BM-residing myeloma }\end{array}$ & [85] \\
\hline OPM2 or primary MM & $\begin{array}{l}\text { Human fetal bone } \\
\text { xenograft in NOD/SCID/IL2R } \gamma^{\text {null }}\end{array}$ & BM tropism & $\begin{array}{l}\text { Adoptive transfer } \\
\text { (expanded human NK cells) }\end{array}$ & Yes & [98] \\
\hline ARP-1 & NOD/SCID/IL2R $\gamma^{\text {null }}$ & BM tropism & $\begin{array}{l}\text { Adoptive transfer } \\
\text { (umbilical cord blood-derived } \\
\text { expanded human NK cells) }\end{array}$ & Yes & [100] \\
\hline RPMI-8226 or ARH-77 & NOD/SCID & SC plasmacytoma & $\begin{array}{l}\text { Adoptive transfer } \\
\text { (anti-CD138 CAR NK cells) }\end{array}$ & Yes & [110] \\
\hline IM9 & NSG & BM tropism & $\begin{array}{l}\text { Adoptive transfer } \\
\text { (anti-CS1-CAR NK cells) }\end{array}$ & Yes & [107] \\
\hline IM9 or MM1.S & NSG & BM tropism & $\begin{array}{l}\text { Adoptive transfer } \\
\text { (anti-CS1-CAR T cells) }\end{array}$ & Yes & [111] \\
\hline OPM2 & NOD/SCID/IL2R $\alpha^{\text {null }}$ & BM tropism & $\begin{array}{l}\text { Adoptive transfer } \\
\text { (anti-CD56 CAR T cells) }\end{array}$ & Yes & [113] \\
\hline MM1.S & NSG & BM tropism & $\begin{array}{l}\text { Adoptive transfer } \\
\text { (anti-CD44v6 CAR T cells) }\end{array}$ & Yes & [117] \\
\hline
\end{tabular}

cells (PBMCs), a potent GvM effect with complete tumor eradication was observed in the U266 MM model following the development of xenogeneic GvHD. Lower doses of PBMCs did not lead to tumor clearance, and almost all these mice were free from GvHD, underlining the link between GvM and GvHD in this model. When inoculating the less immunogenic MM cell line RPMI-8226/S, the GvM response was poor. Nevertheless, these mice developed GvHD, underlining that less immunogenic tumors can evade the GvM response despite the occurrence of GvHD [83].

Another xenogeneic GvM model has been described by Freeman et al. After injection of GFP/luciferase-transfected human RPMI8226 human MM cells into CD122-depleted NOD-SCID mice, they obtained a MM model with bone marrow infiltration and bone lesions. Adoptive transfer of human naive T cells into myeloma-bearing mice transiently suppressed myeloma growth and significantly prolonged survival. In this model, myeloma cells induced the generation of allo-reactive $\mathrm{T}$ cells in the infiltrated bones that exerted cytotoxic activity against resident myeloma cells. Further analysis of allo-reactive $\mathrm{T}$ cells revealed a pronounced in vivo proliferation of CD8 T cells that became the dominant T-cell type. Surprisingly, non-conventional, double-positive $\mathrm{CD} 8{ }^{+} \mathrm{CD} 4^{+}$cell levels also increased in myeloma-infiltrated bones. Both CD8 and double-positive T-cell subsets had an effector memory phenotype, and MHC I expression on myeloma cells and cell contact with $\mathrm{T}$ cells was required for CD8 T-cell proliferation and double positive T-cell development. Although the function of double positive T cells is not completely understood, a higher proportion of these cells express cytotoxic mediators such as IFN- $\gamma$ and perforin compared to CD8 T cells, suggesting that they could be involved in the GvM effect as well [84].

In order to study the effect of Treg infusions on the GvM and GvHD effect, RAG2 ${ }^{-1-} \gamma \mathrm{c}^{-/-}$immunodeficient mice bearing various human MM tumors were infused with human PBMCs alone or together with cultured autologous Tregs [85]. Human PBMC infusions alone induced variable GvM responses, depending on the degree of immunogenicity and growth rate of the myeloma cells. In addition, lethal xenogeneic GvHD was observed. Co-infusion of Tregs inhibited lethal xenogeneic GvHD, as observed by other groups of investigators [86], and did not impair the GvM response against myeloma residing in the bone marrow. However, it did impair anti-tumor responses against myeloma growing outside of the bone marrow. In view of these results, the authors showed that the bone marrow stroma is able to neutralize the suppressive activity of Tregs through the production of IL-1 $\beta$ and IL-6. In addition, Tregs could convert into Th17 cells in the bone marrow microenvironment of the recipient mice [85].

\section{Adoptive cell transfer in multiple myeloma}

Because the modalities of transplantation and adoptive transferbased therapies sometimes overlap, we chose to categorize therapies in which transplanted cells can give rise to immune reconstitution in the recipients, i.e. mice that are immunodeficient and/or underwent a conditioning treatment, as a transplantation-based immunotherapy. In contrast, adoptive cell transfer mainly aims at transmitting specific immunological and functional characteristics of the transferred cells into recipients, which might remain completely immunocompetent, in order to enhance the anti-tumor immune response.

\subsection{Adoptive T-cell transfer}

Adoptive transfer of Tregs from 5T2MM-bearing immunocompetent C57/KalwRij mice into syngeneic mice led, in contrast to Treg infusions in the previously described xenogeneic transplantation model [85], to increased progression of MM disease in recipient mice [87]. These results suggest that cultured Tregs in xenogeneic murine transplantation models are susceptible to bone marrow stroma-mediated neutralization of their suppressive activity, while Tregs isolated from myelomabearing syngeneic mice may be less susceptible to this neutralization 
or present a more suppressive phenotype. Thus, additional studies are needed to elucidate these findings.

Several other adoptive T-cell transfer strategies have been explored in murine models and some of these strategies are now being translated to the clinic. 5T33MM myeloma cells express NKG2D ligands and the adoptive transfer of $\mathrm{T}$ cells expressing a chimeric NKG2D receptor (chNKG2D) fused to the $\mathrm{CD} 3 \zeta$ cytoplasmic domain was tested in 5T33MM-bearing mice. Two infusions of chNKG2D T cells led to tumor eradication in all animals, both through a direct anti-tumor effect and by enhancing host T- and NK-cell immune responses. Moreover, surviving mice developed a protective and specific immune response against myeloma re-challenge, suggesting that chNKG2D T-cell adoptive therapy may be an effective form of immunotherapy in MM [88].

Anti-tumor effects of adoptively transferred Id-specific T cells have also been demonstrated. Hong et al. generated CD8 CTL, CD4 Th1 and Th2 Id-specific T-cell clones from C57/KalwRij mice previously vaccinated with Id-pulsed DC. Adoptive transfer of Id-specific CD8 CTL and Th1 clones into 5TGM1-myeloma bearing mice resulted in myeloma eradication. In contrast, administration of Th2 cells had no effect, suggesting that CTL and Th1 cells are tumoricidal [23]. Bogen et al. demonstrated that adoptive T-cell transfer from TCR-transgenic mice, whose T cells recognize an Id-peptide derived from the murine MOPC315 myeloma protein, conferred anti-myeloma immunity to SCID mice challenged with MOPC315.4 tumors. CD4 T cells are essential for this protection as CD4 depletion led to tumor development in all the challenged mice, whereas the role of CD8 T cells is less clear, as some but not all of the mice developed tumors following CD8 depletion [89].

A synergistic effect between adoptive T-cell therapy and intratumoral gene transfer of lymphotactin or IFN- $\gamma$-inducible protein-10 (IP-10), which are chemoattractants for T cells, has been shown in Balb/c mice challenged with SP2/0 myeloma tumors [90,91]. In addition, inoculation of modified VKCK mouse myeloma cells that secrete the fusion protein RM4/IFN-tau in syngeneic Balb/c mice yielded an immune response that involved CD8 CTLs. In fact, adoptive transfer of T-cell enriched spleen cells or CTLs conferred protection against more aggressive parental VKCK cells in this model [92]. Vaccination of syngeneic mice with IFN- $\gamma$-secreting VKCK cells that express increased levels of MHC I and MHC II resulted in a protective immune response against the parental VKCK myeloma challenge. This protection was mediated by both cytolytic CD4 and CD8 T cells. In addition, these tumorspecific CD4 T cells are tumoricidal in adoptive transfer experiments [93]. Vaccination against SP2/0 myeloma by transfer of tumor antigenspecific lymphocytes into lymphopenic Balb/c mice, immunized with IL-21-secreting SP2/0 myeloma cells, was successful [94]. Whether gene therapy of MM cells or the described vaccination approaches can be translated to the clinic remains to be determined.

\subsection{Adoptive NK-cell transfer}

In contrast to T cells, NK cells do not require pre-activation or immunization in order to recognize and kill target tumor cells [95]. The therapeutic potential of NK-cell adoptive transfer was demonstrated in the 5TMM myeloma model. In this model, IL-2 administration to MMbearing mice significantly prolonged survival. This effect was abolished by in vivo depletion of NK cells but not CD8 T cells. Moreover, activated NK cells had the capacity to kill 5TMM cells in vitro. Finally, a combination of activated NK-cell adoptive transfer with systemic IL-2 treatment resulted in an in vivo anti-MM effect that was dose-dependent on the number of transferred NK cells [96]. Of note, a similar approach was undertaken in MM patients that were infused with IL2-stimulated KIR-Lmismatched haplo-identical NK cells. Although this approach appeared safe and feasible, several limitations became apparent, such as the difficulty to collect a sufficiently high dose of allo-reactive NK cells by leukapheresis, resulting in a limited eradication of MM cells, and the absence of appropriately KIR-L mismatched donors for one third of otherwise eligible patients [97]. These limitations led researchers to evaluate the applicability of in vitro expansion of reactive NK cells. Garg et al. recently described the expansion of NK cells from both MM patients and healthy donors by co-culturing PBMCs with modified K562 cells, a human leukemia cell line, and confirmed the in vitro cytolytic activity of these expanded NK cells against MM cell lines and primary MM cells [98]. Blocking studies identified that multiple NK-cell receptors work in a concerted manner to achieve perforin-dependent cytolysis. Furthermore, adoptive transfer of these expanded NK cells inhibited tumor development in a NK-cell dose-dependent manner in a humanized xenograft MM model, in which fetal human bones were implanted into immunodeficient NOD/scid/IL2R $\gamma^{\text {null }}$ mice, followed by inoculation with primary MM cells or the human myeloma cell line OPM2 [98]. A phase II clinical trial examining the therapeutic effect of expanded NK cells in relapsing high-risk MM patients is currently ongoing (ClinicalTrial.gov \# NCT01313897). In this study, NK cells will be administrated after lymphocyte depletion to facilitate further expansion by Treg-depletion and increased availability of homeostatic cytokines. In addition, patients will be treated with bortezomib, which is known to downregulate MHC I, increase TRAIL-mediated apoptosis and upregulate DNAM-1 and NKG2D NK-cell ligands to further sensitize MM cells to NK cell-mediated lysis [98].

As an alternative, the use of human umbilical cord blood instead of allogeneic PBMCs as an NK-cell source was investigated [99]. Functional NK cells could be obtained after in vitro expansion with IL-2. Moreover, NK-cell expansion from cryopreserved cord blood units using artificial antigen-presenting feeder cells was recently reported. The expanded NK cells displayed in vitro cytotoxicity against several human myeloma cell lines, and administration of these cells delayed tumor formation and prolonged survival of MM-bearing mice in a xenogeneic mouse model in which ARP-1 human myeloma cells were grafted in NOD/scid/ IL2R $\alpha^{\text {null }}$ mice [100]. In addition, approaches to enhance NK-cell activity are also explored. For example, IPH2101, a monoclonal antibody that blocks KIR-ligand interaction, in combination with lenalidomide augments the killing of autologous MM cells by NK cells [101]. In fact, treatment of mice bearing the lenalidomide-resistant RMA T-cell lymphoma with this combination led to in vivo tumor elimination [102]. Recently, the results of a phase I and a phase II clinical trial with IPH2101 have been reported in patients with relapsed/refractory or smoldering MM, respectively $[103,104]$. Although deemed safe, the phase II clinical trial showed no clinical response to IPH2101 alone. Altogether, these studies suggest that increasing NK-cell sensitivity or activity in MM patients prior to adoptive NK-cell transfer might be useful.

\subsection{Adoptive chimeric antigen receptor $T$ \& NK-cell transfer}

The anti-myeloma effects of both $\mathrm{T}$ and NK cells can be further increased by transfecting these cells with chimeric receptors specific for cell-surface molecules expressed on MM cells. These antigens include the common plasma cell markers CD38 and CD138, but also less characteristic targets (Table 3 ). The extracellular domain of a chimeric antigen receptor (CAR) consists of the Fab region of an antibody, typically engineered into a single-chain variable fragment and yielding specificity to the CAR, whereas the intracellular domain is derived from the human TCR signaling domain (CD3 $\zeta$ ), which may be fused to additional costimulatory proteins that promote $\mathrm{T}$-cell proliferation, cytokine release and resistance to apoptosis $[105,106]$. CARs were initially transfected into T cells and more recently this approach was also tested in NK cells.

Chu et al. engineered human NK cells to express a CAR that is specific to CS1 [107]. CS1 is a cell surface glycoprotein that is highly expressed on MM cells, while expression is low on NK cells, some T-cell subsets, normal plasma cells, and negligible on myeloid cells, hematopoietic stem cells and the majority of healthy tissues [108]. Although the exact role of CS1 in normal plasma cells is unknown, CS1 co-localizes with CD138 on the surface of MM cells and promotes MM-cell adhesion and clonogenic growth [109]. The intracellular part of anti-CS1 CAR (CS1 CAR) contains a CD28-CD3 $\zeta$ co-stimulatory signaling domain 
Table 3

Molecular targets used for chimeric antigen receptor-based immunotherapy in murine multiple myeloma models.

\begin{tabular}{|c|c|c|c|c|}
\hline \multirow[t]{2}{*}{ Antigen } & \multirow[t]{2}{*}{ Function } & \multicolumn{2}{|l|}{ Expression } & \multirow[t]{2}{*}{ Ref } \\
\hline & & Normal cells & Myeloma cells & \\
\hline CD38 & $\begin{array}{l}\text { Cell surface glycoprotein, ectoenzyme that } \\
\text { synthesizes cyclic ADP-ribose }\end{array}$ & $\begin{array}{l}\text { - Mature B and T cells (low levels) } \\
\text { - NK cells } \\
\text { - Common myeloid progenitors }\end{array}$ & $\begin{array}{l}\text { Surface expression at variable } \\
\text { levels in the majority of patients }\end{array}$ & [112] \\
\hline CD138 & $\begin{array}{l}\text { Membrane heparan sulfate-containing } \\
\text { proteoglycan, participates in } \\
\text { cell-matrix interactions }\end{array}$ & $\begin{array}{l}\text { - Pre-B cells and plasma cells } \\
\text { (lost on circulating/mature cells) } \\
\text { - Squamous epithelial cells } \\
\text { (strong membranous/some } \\
\text { cytoplasmic expression) }\end{array}$ & $\begin{array}{l}\text { Expression at variable levels } \\
\text { by most myeloma cells }\end{array}$ & [110] \\
\hline CD56 & $\begin{array}{l}\text { Cell surface glycoprotein, mediates } \\
\text { cell-cell and cell-matrix interactions }\end{array}$ & $\begin{array}{l}\text { - Nervous system } \\
\text { - Various epithelia } \\
\text { - Hematopoietic system: NK cells } \\
\text { (80-90\%), NKT cells }\end{array}$ & $\begin{array}{l}\text { Strong expression in } 78 \% \text { of } \\
\text { MM patients }\end{array}$ & [113] \\
\hline Kappa light chain & Immunoglobulin light chain & - Mature B cells & $\begin{array}{l}\text { Surface expression in } 35 \% \text { of } \\
\text { MM patients }\end{array}$ & {$[152]$} \\
\hline Lewis $Y$ antigen & $\begin{array}{l}\text { Cell surface antigen present on glycoconjugates, } \\
\text { involved in cellular motility and adhesion }\end{array}$ & $\begin{array}{l}\text { - Epithelial cells (lung, breast, } \\
\text { prostate, stomach, pancreas, uterus and ovary) } \\
\text { - Peripheral blood granulocytes }\end{array}$ & Expression in $52 \%$ of MM patients & [116] \\
\hline BCMA & $\begin{array}{l}\text { TNFR-family protein, pro-survival upon } \\
\text { binding to its ligands BAFF and APRIL }\end{array}$ & $\begin{array}{l}\text { - Mature B cells } \\
\text { - Plasma cells (selectively } \\
\text { induced during differentiation) } \\
\text { - Nearly absent on naive and memory B cells }\end{array}$ & $\begin{array}{l}\text { Expression by all myeloma } \\
\text { cells and by myeloma cell } \\
\text { lines }(4 / 5)\end{array}$ & [115] \\
\hline CD44v6 & $\begin{array}{l}\text { Transmembrane glycoprotein, CD44 isoform, } \\
\text { hyaluronate-binding adhesion molecule. }\end{array}$ & $\begin{array}{l}\text { - Squamous epithelia (skin, cervix, } \\
\text { oral mucosa, esophagus) } \\
\text { - Myoepithelia (breast, prostate) } \\
\text { - Type II pneumocytes }\end{array}$ & $\begin{array}{l}\text { Expression in } 43 \% \text { to } 87 \% \text { of } \\
\text { symptomatic MM patients }\end{array}$ & [117] \\
\hline CS1 & $\begin{array}{l}\text { Cell surface glycoprotein, involved in } \\
\text { cell-cell and cell-matrix interactions }\end{array}$ & $\begin{array}{l}\text { - Plasma cells } \\
\text { - NK cells and subsets of T cells } \\
\text { - Activated monocytes and DCs }\end{array}$ & $\begin{array}{l}\text { Expression (RNA/protein) in } \\
\text { (all/majority) of MM patients }\end{array}$ & {$[107,111]$} \\
\hline
\end{tabular}

that enhances NK-cell activity by increasing their cytotoxicity and IFN- $\gamma$ production. The anti-MM function of CS1-CAR NK cells was evaluated in vitro and in vivo in an IM9-Luc-xenografted NSG mouse model [107]. CS1-CAR NK cells had an increased cytolytic activity against CS1-positive myeloma cell lines compared to unmodified NK cells. Following adoptive transfer of CS1-CAR NK cells, the total tumor load was significantly decreased in IM9-Luc tumor-bearing mice and their survival was significantly prolonged compared to mice that received mock-transduced control NK cells [107]. Similar results were obtained with CAR NK cells directed against CD138 in a MM xenograft NODSCID model. Interestingly, high-dose irradiation did not attenuate the cytotoxicity of these cells but instead intensified the anti-tumor response [110].

Using the CS1-CAR construct, Chu et al. also generated CS1 CAR T cells and obtained similar results as with the NK cells. CS1-CAR T cells showed enhanced in vitro cytotoxicity against CS1-expressing myeloma cells, and adoptive transfer into a NSG xenograft mouse model efficiently suppressed the growth of human MM.1S and IM9 myeloma cells and significantly prolonged survival [111]. Multiple additional antigens have been used as targets for the generation of CAR T cells. Anti-CD38 CAR T cells showed a highly cytotoxic, dose-dependent effect on $\mathrm{CD}_{3}{ }^{+}$ RPMI8226 MM cells and primary MM cells while no cytotoxicity was observed on CD38- MM cell lines [112]. CD56 is strongly expressed on malignant plasma cells in $78 \%$ of patients with myeloma and represents another potential immunotherapeutic target. Anti-CD56 CAR T cells showed antigen-dependent proliferation, cytokine secretion and cytotoxicity when stimulated with CD56 positive myeloma cells. In addition, intravenous injection of anti-CD56 CAR T cells in OPM2bearing NOD/scid/IL2R $\alpha^{\text {null }}$ mice resulted in a dose-dependent tumor eradication with persistent anti-CD56 CAR T cells that could be retrieved from the circulation even 3 months after injection [113]. Whether these mice are less prone to develop tumors when re-challenged with an OPM2 injection is not clear yet. B-cell maturation antigen (BCMA) is expressed by MM cell lines and on the surface of primary human MM cells [114]. Anti-BCMA CAR T cells produced large amounts of IFN- $\gamma$ in co-cultures with BCMA-expressing MM cell lines and were able to kill human primary MM cells and MM cell lines that express BCMA (H929 and RPMI-8226). Moreover, anti-BCMA CAR T cells eliminated subcutaneous plasmacytomas derived from RPMI-8226 cells in NSG mice, resulting in the survival of these mice, whereas controls died with progressive tumors [115]. The Lewis-y (Le ${ }^{\mathrm{y}}$ ) antigen is a blood grouprelated antigen that is expressed in over $70 \%$ of epithelial cancers and in approximately half of primary myeloma samples. Anti-Lewis CAR T cells secreted IFN- $\gamma$ in response to RPMI-8226 human myeloma cells and specifically lysed Le ${ }^{\mathrm{y}}$-positive myeloma cells. In addition, intravenous injections of anti-Lewis CAR T cells in myeloma-bearing NOD/ SCID mice grafted with RPMI-8226 cells resulted in a significant improvement of survival compared with mice treated with nontransduced T cells [116]. Anti-CD44v6 CAR T cells were generated by retroviral transduction of T cells with a CAR that consists of the Fab domain of the anti-CD44v6 antibody bivatuzumab linked to an intracellular $\mathrm{CD} 3 \zeta / \mathrm{CD} 28$ domain [117]. This yielded T cells that displayed the appropriate in vitro anti-CD44v6 effector functions and that inhibited MM tumor formation in xenograft models. However, monocytopenia was observed in mice treated with anti-CD44v6 CAR T cells due to the expression of this antigen on circulating monocytes. This toxic side-effect could be avoided by co-transduction of a suicide gene that ensured a rapid elimination of CD44v6-CAR T cells. Taken together, these studies suggest that adoptive transfer with CAR NK and $T$ cells is a promising immunotherapy for MM. Currently, two clinical trials using CAR T cells to treat MM are ongoing, using CARs which target the kappa immunoglobulin light chain and CD138 [118].

\section{Dendritic cell vaccination}

In the past decade, DC vaccination has been explored as a targeted therapeutic approach for the treatment of cancer and of MM in 
particular. However, many hurdles are encountered when developing a DC vaccination strategy, such as choosing an optimal antigen, mode of delivery and timing of vaccination, and how to overcome the immune paresis of myeloma itself [119].

Myeloma vaccination was first attempted in the immunocompetent MOPC315 model [120,121]. These cells express a specific IgA paraprotein (M315), and prophylactic vaccination with this protein protected mice against inoculation with MOPC315 cells [122]. Subsequently, a specific Id-peptide of M315 presented in an MHC II context was discovered (amino acid 91-101 of the $\gamma 2$ light chain) [123,124], and a transgenic mouse strain expressing a TCR specific for this Idpeptide was generated [125]. Immune rejection in these TCR transgenic mice is dependent on paraprotein secretion by the injected MOP315 cells. The paraprotein is internalized by DCs through endocytosis [126], processed and presented in an MHC II context, resulting in the activation of Id-specific transgenic CD4 T cells in the draining lymph nodes. These cells then migrate to the incipient tumor site and secrete IFN- $\gamma$ that activates macrophages, resulting in a further inhibition of tumor growth [127].

Of note, once the tumor burden exceeds a certain threshold in the MOPC315 model, with M-protein levels exceeding $50 \mu \mathrm{g} / \mathrm{ml}$, central and peripheral tolerance is induced $[37,128]$. The concept of T-cell exhaustion caused by Id-protein in established disease is further supported by a murine study in which the combination of Id-pulsed DC vaccination with syngeneic SCT was evaluated [129]. Briefly, Balb/c mice were inoculated with HOPC-1F cells and tumor-bearing animals were immunized with an Id-pulsed DC vaccine that resulted in a prolonged survival of these mice compared to controls. However, all animals eventually died from their disease. Mice receiving syngeneic transplantation underwent 7.5 Gy total body irradiation 2 days after HOPC inoculation, followed by the transfer of G-CSF mobilized syngeneic peripheral blood progenitor cells. Similar to Id-pulsed DC vaccination as sole therapy, syngeneic SCT alone did not result in long-term survival. Conversely, when combining Id-pulsed DC vaccination with syngeneic SCT, longterm survival was observed in $78 \%$ of animals, suggesting that Id-T cell exhaustion was less prevalent.

As the immunogenicity of Id-vaccines can be poor, homodimeric fusion DNA vaccines, delivered by intramuscular injection, were evaluated in the MOPC315 model [130]. The fusion proteins, called vaccibodies, consist in the variable fragment of an Id single chain (the tumor antigen) and a targeting moiety directed towards antigen-presenting cells (APC), for example the single chain variable fragment of APC-specific antibodies (anti-MHC II, anti-CD40) or chemokines (MIP1 $\alpha$, RANTES) [131-134]. Structural modifications to vaccibodies, like the generation of bivalent vaccines and the introduction of xenogeneic sequences, further enhanced the effectiveness of the chemokine-Id DNA vaccines [134]. Using a similar technique, a dickkopf-1 hybrid DNA vaccine was shown to confer immunity in mice inoculated with MOPC-21 or with established plasmacytoma [135]. In addition, co-injection of PD-L1blocking or CD134-agonist antibodies further enhanced the vaccination efficacy, underscoring the potential of interfering with checkpoint mediators. This finding was corroborated in a separate study exploring the efficacy of PD-L1 blockade in a whole-cell vaccination model in 5 T33 mice [136]. The use of dickkopf- 1 as a tumor antigen has clinical promise because its expression is restricted to myeloma cells, with the exception of prostate and placental tissues. The importance of antigen choice and thus optimal vaccine formulation was further demonstrated in a murine model of J588L plasmacytoma, i.e. a J588 cell line that has lost the expression of antibody $\mathrm{H}$ chain. In this model, Id-keyhole limpet hemocyanin (KLH)-loaded DC vaccines were inefficient to prevent tumor development in J588L-inoculated mice, in contrast to J588 mice. However, direct intra-tumoral injection of naive DCs and subcutaneous injections of DCs loaded with irradiated tumor cells did result in a significant anti-myeloma effect [137]. These findings support the notion that $\mathrm{T}$-cell responses after paraprotein-pulsed DC vaccination are primarily directed against peptides derived from the complementarity determining regions of the $\mathrm{H}$-chain, and may be futile in patients with light chain myeloma. Conversely, vaccination with tumor cell-loaded DC may induce an effective anti-tumor response. This is further underlined by the finding that tumor lysate-pulsed DCs were found to be superior to Id-KLH-pulsed DCs in terms of promoting anti-tumor immunity [138].

Fusion of myeloma cells to DCs could circumvent the cumbersome choice of a tumor antigen. Proof of principle of this approach in a murine myeloma model was delivered by fusing irradiated native J558 and engineered J558 cells expressing IL-4 with immature and mature Balb/ c bone marrow-derived DCs [139]. Maturation of DCs in vitro was obtained by adding a high dose of GM-CSF and IL-4 to the culture medium. After prophylactic vaccination, especially the IL-4-secreting J558/ mature DC fusion vaccine was able to induce protective immunity against J558 tumor challenge, illustrating the importance of the maturation status of DCs and the therapeutic potential of gene-modified tumor fusion vaccines. Similar results were obtained with an analogous model using CD40L-expressing J558 cells [140].

Prophylactic vaccination with both Id-KLH protein and Id-KLHpulsed DCs was able to protect mice from developing myeloma in the 5TGM1 myeloma model. However, when used as a therapeutic vaccine, only the Id-KLH-pulsed DC vaccine was able to retard growth and induce tumor regression. In $60 \%$ of the DC-vaccinated mice the preexisting tumor could be eradicated and these animals were resistant to subsequent tumor re-challenge. The difference in vaccination efficacy was most likely due to an increased cellular immune response utilizing DC vaccination compared to Id-KLH protein since more anti-Id antibodies were observed in the former setting [141].

Several clinical trials investigating DC vaccination in MM patients are currently ongoing. Results of phase II trials using Id-pulsed DC vaccines confirmed the safety of DC vaccination and the induction of a specific anti-myeloma immune response in patients [142,143]. However, clinical efficacy of Id-pulsed DC vaccines could not be demonstrated yet, despite disease stabilization in a majority of patients [143]. In another phase II clinical trial, minimal residual disease was targeted in myeloma patients after auto-SCT using DC/tumor fusion vaccines. The results were encouraging, as DC/tumor fusion vaccination during the post-transplantation period resulted in an expansion of myelomaspecific T cells and a reduction of minimal residual disease [144].

\section{Conclusions}

Over the last few years, the idea of blocking cancer progression through immunological means is slowly becoming a reality. Indeed, harnessing the inherent properties of the immune system to attack tumors will certainly propel immunotherapy to the forefront of cancer treatment. Unfortunately, durable immunological control of myeloma is still rare, and current research aims at optimizing immunotherapeutic approaches and their clinical results.

Murine myeloma models are an important mean to achieve this goal, but they can present some limitations for pre-clinical studies. In order to achieve progress in MM immunotherapy, the use of mouse models that closely recapitulate human disease, both in development of the disease and in immunological response of the host, may prove to be essential. Tumor localization within the bone marrow, obtained after intravenous injection or direct intra-osseous injection, is crucial for studying the disease in a representative tumor microenvironment. This bone marrow localization is often indispensable for myelomarelated symptoms such as bone lesions and cytopenia. Hence, these models allow the assessment of new therapeutic approaches in a representative tumor microenvironment at a relevant MM stage. Optimization of existing murine models is feasible. For example, a cell line named MOPC315.BM showing bone marrow tropism was recently derived from MOPC315 cells [145]. Whereas MM has generally a low progression rate, with a low proliferative index for primary myeloma cells, most of the murine myeloma models make use of highly proliferative 
and blastic cell lines with tumor development that only takes several weeks. Thus, the MM growth and differentiation characteristics and associated immunological alterations might have an impact on the response to immunotherapy. A comparison of immunological responses to MM development in different murine myeloma models would be of great interest in this context. Several findings also highlight the importance of timing for efficient immunotherapy. For example, the disappointing results of anti-Id vaccination trials $[146,147]$ might be due to a deletion of Id-specific CD4 T cells in most MM patients at the time of diagnosis. Thus, the optimal time of vaccination would be in a state of low residual disease burden and after high-dose chemotherapy, a time point at which a new repertoire of $\mathrm{T}$ cells undergoes thymic education and Treg levels are low [148]. Finally, promising opportunities for testing immunotherapeutic concepts lie in the use of genetic inducible murine models of MM since these models resemble human disease with a similar genetic landscape. In addition, they display a more indolent tumor growth, with tumor development that takes up to 18 months, that allows for treatment initiation at a stage more resembling to the clinical situation. Several of such models have been reported, including transgenic $\mathrm{E} \mu-\mathrm{c}-\mathrm{MAF}$ and $\mathrm{E} \mu-\mathrm{XBP} 1 \mathrm{~s}$ mice that overexpress these myeloma-associated genes in an $\mathrm{E} \mu$-dependent B-cell specific manner $[149,150]$. In addition, Chesi et al. generated Vk*MYC transgenic mice in which the activation of MYC is under the control of the Igא light chain gene regulatory elements, developing tumors that are highly homologous to those observed in human MM [151].

Although allo-SCT is efficiently used for the treatment of several other hematological malignancies, its efficiency in MM remains unsatisfactory, possibly due to immunological suppression of the graft by residual MM cells. Highly suppressive Tregs expand and accumulate in the bone marrow after allo-SCT [62], and these cells might be able to convert into myeloma-promoting Th17 cells [25,85]. Murine studies suggest that combining allo-SCT with Id- or DC vaccination provides a possible solution to these issues $[81,82]$. In addition, new immunotherapeutic strategies targeting Th17 cells, but also immune suppressive cells like MDSCs and Tregs, would be of great interest.

To conclude, several murine models of MM are available and are being developed that allow the study of anti-myeloma immunotherapy. These models permit detailed monitoring of the anti-myeloma immune response following treatment with novel immunotherapeutic approaches. Recently, some of these studies gave rise to clinical trials, bringing cellular immunotherapy of MM from preclinical models to the bedside.

\section{Acknowledgements}

This work has been supported by grants from the Belgian Foundation against Cancer (\#2012-196), Fonds de la Recherche Scientifique Médicale (\# 3.4593.11), the Fonds National de la Recherche Scientifique (\#7.4527.12,\#7.4624.13), Fonds Léon Fredericq and Fonds Spéciaux de la Recherche - University of Liège (\#14/67, \#11/37). MB and JM are Télévie Research Assistants.

\section{References}

[1] J. Caers, I. Vande broek, H. De Raeve, L. Michaux, F. Trullemans, R. Schots, et al. Multiple myeloma-an update on diagnosis and treatment, Eur. J. Haematol. 81 (5) (2008) 329-343.

[2] M. Potter, C.R. Boyce, Induction of plasma-cell neoplasms in strain BALB/c mice with mineral oil and mineral oil adjuvants, Nature 193 (1962) 1086-1087.

[3] J. Radl, J.W. Croese, C. Zurcher, M.H. Van den Enden-Vieveen, A.M. de Leeuw, Animal model of human disease. Multiple myeloma, Am. J. Pathol. 132 (3) (1988) 593-597.

[4] I.R. Garrett, S. Dallas, J. Radl, G.R. Mundy, A murine model of human myeloma bone disease, Bone 20 (6) (1997) 515-520.

[5] I. Bruns, R.P. Cadeddu, I. Brueckmann, J. Frobel, S. Geyh, S. Bust, et al., Multiple myeloma-related deregulation of bone marrow-derived $\mathrm{CD} 34(+)$ hematopoietic stem and progenitor cells, Blood 120 (13) (2012) 2620-2630.

[6] M.W. Roeven, W. Hobo, N. Schaap, H. Dolstra, Immunotherapeutic approaches to treat multiple myeloma, Hum. Vaccin. Immunother. 10 (4) (2013).
[7] G. Cook, J.D. Campbell, Immune regulation in multiple myeloma: the host-tumour conflict, Blood Rev. 13 (3) (1999) 151-162.

[8] S.J. Harrison, G. Cook, Immunotherapy in multiple myeloma-possibility or probability? Br. J. Haematol. 130 (3) (2005) 344-362.

[9] H. Quach, D. Ritchie, A.K. Stewart, P. Neeson, S. Harrison, M.J. Smyth, et al., Mechanism of action of immunomodulatory drugs (IMiDS) in multiple myeloma, Leukemia 24 (1) (2010) 22-32.

[10] C.A. Dasanu, Immune alterations in untreated and treated multiple myeloma, J. Oncol. Pharm. Pract. 18 (2) (2012) 257-263.

[11] S. Feyler, P.J. Selby, G. Cook, Regulating the regulators in cancerimmunosuppression in multiple myeloma (MM), Blood Rev. 27 (3) (2013) 155-164.

[12] M. Rossi, C. Botta, P. Correale, P. Tassone, P. Tagliaferri, Immunologic microenvironment and personalized treatment in multiple myeloma, Expert. Opin. Biol. Ther. 13 (Suppl. 1) (2013) S83-S93.

[13] K.H. Mills, J.C. Cawley, Abnormal monoclonal antibody-defined helper/suppressor T-cell subpopulations in multiple myeloma: relationship to treatment and clinical stage, Br. J. Haematol. 53 (2) (1983) 271-275.

[14] H.M. Serra, M.J. Mant, B.A. Ruether, J.A. Ledbetter, L.M. Pilarski, Selective loss of CD4 + CD45R + T cells in peripheral blood of multiple myeloma patients, J. Clin. Immunol. 8 (4) (1988) 259-265.

[15] M.J. Hicks, B.G. Durie, D.J. Slymen, Low circulating T-helper cells in relapsing multiple myeloma, J. Clin. Lab. Anal. 3 (4) (1989) 202-208.

[16] J.F. San Miguel, M. Gonzalez, A. Gascon, M.J. Moro, J.M. Hernandez, F. Ortega, et al., Lymphoid subsets and prognostic factors in multiple myeloma. Cooperative group for the study of monoclonal gammopathies, Br. J. Haematol. 80 (3) (1992) 305-309.

[17] H. Ogawara, H. Handa, T. Yamazaki, T. Toda, K. Yoshida, N. Nishimoto, et al., High Th1/Th2 ratio in patients with multiple myeloma, Leuk. Res. 29 (2) (2005) $135-140$.

[18] P. Schutt, D. Brandhorst, W. Stellberg, M. Poser, P. Ebeling, S. Muller, et al., Immune parameters in multiple myeloma patients: influence of treatment and correlation with opportunistic infections, Leuk. Lymphoma 47 (8) (2006) 1570-1582.

[19] B. Maecker, K.S. Anderson, M.S. von Bergwelt-Baildon, E. Weller, R.H. Vonderheide, P.G. Richardson, et al., Viral antigen-specific CD8 + T-cell responses are impaired in multiple myeloma, Br. J. Haematol. 121 (6) (2003) 842-848.

[20] H. Murakami, H. Ogawara, H. Hiroshi, Th1/Th2 cells in patients with multiple myeloma, Hematology 9 (1) (2004) 41-45.

[21] P. Fietta, G. Delsante, The effector T helper cell triade, Riv. Biol. 102 (1) (2009) 61-74.

[22] A. Sharma, R. Khan, S. Joshi, L. Kumar, M. Sharma, Dysregulation in T helper 1/T helper 2 cytokine ratios in patients with multiple myeloma, Leuk. Lymphoma 51 (5) (2010) 920-927.

[23] S. Hong, J. Qian, J. Yang, H. Li, L.W. Kwak, Q. Yi, Roles of idiotype-specific t cells in myeloma cell growth and survival: Th1 and CTL cells are tumoricidal while Th2 cells promote tumor growth, Cancer Res. 68 (20) (2008) 8456-8464.

[24] G. Gorgun, E. Calabrese, E. Soydan, T. Hideshima, G. Perrone, M. Bandi, et al., Immunomodulatory effects of lenalidomide and pomalidomide on interaction of tumor and bone marrow accessory cells in multiple myeloma, Blood 116 (17) (2010) 3227-3237.

[25] R.H. Prabhala, D. Pelluru, M. Fulciniti, H.K. Prabhala, P. Nanjappa, W. Song, et al., Elevated IL-17 produced by TH17 cells promotes myeloma cell growth and inhibits immune function in multiple myeloma, Blood 115 (26) (2010) 5385-5392.

[26] K.M. Dhodapkar, S. Barbuto, P. Matthews, A. Kukreja, A. Mazumder, D. Vesole, et al., Dendritic cells mediate the induction of polyfunctional human IL17-producing cells (Th17-1 cells) enriched in the bone marrow of patients with myeloma, Blood 112 (7) (2008) 2878-2885.

[27] C.J. Shen, Z.H. Yuan, Y.X. Liu, G.Y. Hu, Increased numbers of T helper 17 cells and the correlation with clinicopathological characteristics in multiple myeloma, J. Int. Med. Res. 40 (2) (2012) 556-564.

[28] J.D. Campbell, G. Cook, S.E. Robertson, A. Fraser, K.S. Boyd, J.A. Gracie, et al., Suppression of IL-2-induced T cell proliferation and phosphorylation of STAT3 and STAT5 by tumor-derived TGF beta is reversed by IL-15, J. Immunol. 167 (1) (2001) 553-561.

[29] D. Atanackovic, T. Luetkens, N. Kroger, Coinhibitory molecule PD-1 as a potential target for the immunotherapy of multiple myeloma, Leukemia 28 (5) (2014) 993-1000.

[30] J. Rosenblatt, B. Glotzbecker, H. Mills, B. Vasir, D. Tzachanis, J.D. Levine, et al., PD-1 blockade by CT-011, anti-PD-1 antibody, enhances ex vivo T-cell responses to autologous dendritic cell/myeloma fusion vaccine, J. Immunother. 34 (5) (2011) 409-418.

[31] D.M. Benson Jr., C.E. Bakan, A. Mishra, C.C. Hofmeister, Y. Efebera, B. Becknell, et al., The PD-1/PD-L1 axis modulates the natural killer cell versus multiple myeloma effect: a therapeutic target for CT-011, a novel monoclonal anti-PD-1 antibody, Blood 116 (13) (2010) 2286-2294.

[32] H. Tamura, M. Ishibashi, T. Yamashita, S. Tanosaki, N. Okuyama, A. Kondo, et al. Marrow stromal cells induce B7-H1 expression on myeloma cells, generating aggressive characteristics in multiple myeloma, Leukemia 27 (2) (2013) 464-472.

[33] P. Moss, G. Gillespie, P. Frodsham, J. Bell, H. Reyburn, Clonal populations of CD4+ and CD8 + T cells in patients with multiple myeloma and paraproteinemia, Blood 87 (8) (1996) 3297-3306

[34] S. Mariani, M. Coscia, J. Even, S. Peola, M. Foglietta, M. Boccadoro, et al., Severe and long-lasting disruption of T-cell receptor diversity in human myeloma after high- 
dose chemotherapy and autologous peripheral blood progenitor cell infusion, Br. J. Haematol. 113 (4) (2001) 1051-1059.

[35] D.M. Sze, G. Giesajtis, R.D. Brown, M. Raitakari, J. Gibson, J. Ho, et al., Clonal cytotoxic T cells are expanded in myeloma and reside in the $\operatorname{CD} 8(+) \operatorname{CD} 57(+)$ CD28(-) compartment, Blood 98 (9) (2001) 2817-2827.

[36] Q. Yi, A. Osterborg, Idiotype-specific T cells in multiple myeloma: targets for an immunotherapeutic intervention? Med. Oncol. 13 (1) (1996) 1-7.

[37] B. Bogen, Peripheral T, cell tolerance as a tumor escape mechanism: deletion of CD4 + T cells specific for a monoclonal immunoglobulin idiotype secreted by a plasmacytoma, Eur. J. Immunol. 26 (11) (1996) 2671-2679.

[38] L.M. Pilarski, E.J. Andrews, M.J. Mant, B.A. Ruether, Humoral immune deficiency in multiple myeloma patients due to compromised B-cell function, J. Clin. Immunol. 6 (6) (1986) 491-501.

[39] A.C. Rawstron, F.E. Davies, R.G. Owen, A. English, G. Pratt, J.A. Child, et al., Blymphocyte suppression in multiple myeloma is a reversible phenomenon specific to normal B-cell progenitors and plasma cell precursors, Br. J. Haematol. 100 (1) (1998) $176-183$.

[40] R.D. Brown, B. Pope, A. Murray, W. Esdale, D.M. Sze, J. Gibson, et al., Dendritic cells from patients with myeloma are numerically normal but functionally defective as they fail to up-regulate CD80 (B7-1) expression after huCD40LT stimulation because of inhibition by transforming growth factor-beta 1 and interleukin-10, Blood 98 (10) (2001) 2992-2998.

[41] M. Urashima, A. Ogata, D. Chauhan, M. Hatziyanni, M.B. Vidriales, D.A. Dedera, et al. , Transforming growth factor-beta1: differential effects on multiple myeloma versus normal B cells, Blood 87 (5) (1996) 1928-1938.

[42] E. Carbone, P. Neri, M. Mesuraca, M.T. Fulciniti, T. Otsuki, D. Pende, et al., HLA class I, NKG2D, and natural cytotoxicity receptors regulate multiple myeloma cell recognition by natural killer cells, Blood 105 (1) (2005) 251-258.

[43] M. Gonzalez, J.F. San Miguel, A. Gascon, M.J. Moro, J.M. Hernandez, F. Ortega, et al, Increased expression of natural-killer-associated and activation antigens in multiple myeloma, Am. J. Hematol. 39 (2) (1992) 84-89.

[44] C. Fauriat, F. Mallet, D. Olive, R.T. Costello, Impaired activating receptor expression pattern in natural killer cells from patients with multiple myeloma, Leukemia 20 (4) (2006) 732-733.

[45] M.V. Dhodapkar, M.D. Geller, D.H. Chang, K. Shimizu, S. Fujii, K.M. Dhodapkar, et al., A reversible defect in natural killer $\mathrm{T}$ cell function characterizes the progression of premalignant to malignant multiple myeloma, J. Exp. Med. 197 (12) (2003) 1667-1676.

[46] D.H. Chang, H. Deng, P. Matthews, J. Krasovsky, G. Ragupathi, R. Spisek, et al., Inflammation-associated lysophospholipids as ligands for CD1d-restricted T cells in human cancer, Blood 112 (4) (2008) 1308-1316.

[47] M. Ratta, F. Fagnoni, A. Curti, R. Vescovini, P. Sansoni, B. Oliviero, et al., Dendritic cells are functionally defective in multiple myeloma: the role of interleukin-6, Blood 100 (1) (2002) 230-237.

[48] R. Brown, A. Murray, B. Pope, D.M. Sze, J. Gibson, P.J. Ho, et al., Either interleukin-12 or interferon-gamma can correct the dendritic cell defect induced by transforming growth factor beta in patients with myeloma, Br. J. Haematol. 125 (6) (2004) 743-748.

[49] M.K. Brimnes, A.J. Vangsted, L.M. Knudsen, P. Gimsing, A.O. Gang, H.E. Johnsen, et al., Increased level of both CD4+FOXP3 + regulatory T cells and CD14+HLA-DR $(-)$ ) low myeloid-derived suppressor cells and decreased level of dendritic cells in patients with multiple myeloma, Scand. J. Immunol. 72 (6) (2010) 540-547.

[50] K. Giannopoulos, W. Kaminska, I. Hus, A. Dmoszynska, The frequency of T regulatory cells modulates the survival of multiple myeloma patients: detailed characterisation of immune status in multiple myeloma, Br. J. Cancer 106 (3) (2012) 546-552.

[51] J.R. Nair, L.M. Carlson, C. Koorella, C.H. Rozanski, G.E. Byrne, P.L. Bergsagel, et al., CD28 expressed on malignant plasma cells induces a prosurvival and immunosuppressive microenvironment, J. Immunol. 187 (3) (2011) 1243-1253.

[52] M.K. Brimnes, I.M. Svane, H.E. Johnsen, Impaired functionality and phenotypic profile of dendritic cells from patients with multiple myeloma, Clin. Exp. Immunol. 144 (1) (2006) 76-84.

[53] D.H. Yang, J.S. Park, C.J. Jin, H.K. Kang, J.H. Nam, J.H. Rhee, et al., The dysfunction and abnormal signaling pathway of dendritic cells loaded by tumor antigen can be overcome by neutralizing VEGF in multiple myeloma, Leuk. Res. 33 (5) (2009) 665-670.

[54] S. Wang, J. Yang, J. Qian, M. Wezeman, L.W. Kwak, Q. Yi, Tumor evasion of the immune system: inhibiting p38 MAPK signaling restores the function of dendritic cells in multiple myeloma, Blood 107 (6) (2006) 2432-2439.

[55] S. Wang, S. Hong, J. Yang, J. Qian, X. Zhang, E. Shpall, et al., Optimizing immunotherapy in multiple myeloma: restoring the function of patients monocyte-derived dendritic cells by inhibiting p38 or activating MEK/ERK MAPK and neutralizing interleukin-6 in progenitor cells, Blood 108 (13) (2006) 4071-4077.

[56] D.E. Joshua, R.D. Brown, P.J. Ho, J. Gibson, Regulatory T cells and multiple myeloma, Clin. Lymphoma Myeloma 8 (5) (2008) 283-286.

[57] R.H. Prabhala, P. Neri, J.E. Bae, P. Tassone, M.A. Shammas, C.K. Allam, et al., Dysfunctional T regulatory cells in multiple myeloma, Blood 107 (1) (2006) 301-304.

[58] M. Beyer, M. Kochanek, T. Giese, E. Endl, M.R. Weihrauch, P.A. Knolle, et al., In vivo peripheral expansion of naive CD4+CD25high FoxP3 + regulatory T cells in patients with multiple myeloma, Blood 107 (10) (2006) 3940-3949.

[59] S. Feyler, M. von Lilienfeld-Toal, S. Jarmin, L. Marles, A. Rawstron, A.J. Ashcroft, et al, CD4 (+)CD25(+)FoxP3 $(+)$ regulatory T cells are increased whilst CD3(+)CD4(-) CD8 (-)alphabetaTCR $(+)$ double negative T cells are decreased in the peripheral blood of patients with multiple myeloma which correlates with disease burden, $\mathrm{Br}$. J. Haematol. 144 (5) (2009) 686-695.
[60] K.R. Muthu Raja, L. Rihova, L. Zahradova, M. Klincova, M. Penka, R. Hajek, Increased $T$ regulatory cells are associated with adverse clinical features and predict progression in multiple myeloma, PLoS One 7 (10) (2012) e47077.

[61] S. Feyler, G.B. Scott, C. Parrish, S. Jarmin, P. Evans, M. Short, et al., Tumour cell generation of inducible regulatory T-cells in multiple myeloma is contact-dependent and antigen-presenting cell-independent, PLoS One 7 (5) (2012) e35981.

[62] D. Atanackovic, Y. Cao, T. Luetkens, J. Panse, C. Faltz, J. Arfsten, et al., $\mathrm{CD} 4+\mathrm{CD} 25+\mathrm{FOXP} 3+\mathrm{T}$ regulatory cells reconstitute and accumulate in the bone marrow of patients with multiple myeloma following allogeneic stem cell transplantation, Haematologica 93 (3) (2008) 423-430.

[63] S. Ostrand-Rosenberg, P. Sinha, Myeloid-derived suppressor cells: linking inflammation and cancer, J. Immunol. 182 (8) (2009) 4499-4506.

[64] G.T. Gorgun, G. Whitehill, J.L. Anderson, T. Hideshima, C. Maguire, J. Laubach, et al., Tumor-promoting immune-suppressive myeloid-derived suppressor cells in the multiple myeloma microenvironment in humans, Blood 121 (15) (2013) 2975-2987.

[65] I.R. Ramachandran, A. Martner, A. Pisklakova, T. Condamine, T. Chase, T. Vogl, et al., Myeloid-derived suppressor cells regulate growth of multiple myeloma by inhibiting T cells in bone marrow, J. Immunol. 190 (7) (2013) 3815-3823.

[66] E. Van Valckenborgh, E. Schouppe, K. Movahedi, E. De Bruyne, E. Menu, P. De Baetselier, et al., Multiple myeloma induces the immunosuppressive capacity of distinct myeloid-derived suppressor cell subpopulations in the bone marrow, Leukemia 26 (11) (2012) 2424-2428.

[67] B. Hoechst, L.A. Ormandy, M. Ballmaier, F. Lehner, C. Kruger, M.P. Manns, et al., A new population of myeloid-derived suppressor cells in hepatocellular carcinoma patients induces CD4(+)CD25(+)Foxp3(+) T cells, Gastroenterology 135 (1) (2008) 234-243.

[68] G. Tricot, D.H. Vesole, S. Jagannath, J. Hilton, N. Munshi, B. Barlogie, Graft-versusmyeloma effect: proof of principle, Blood 87 (3) (1996) 1196-1198.

[69] C. Crawley, M. Lalancette, R. Szydlo, M. Gilleece, K. Peggs, S. Mackinnon, et al., Outcomes for reduced-intensity allogeneic transplantation for multiple myeloma: an analysis of prognostic factors from the Chronic Leukaemia Working Party of the EBMT, Blood 105 (11) (2005) 4532-4539.

[70] A. Krishnan, M.C. Pasquini, B. Logan, E.A. Stadtmauer, D.H. Vesole, E. Alyea 3rd, et al. Autologous haemopoietic stem-cell transplantation followed by allogeneic or autologous haemopoietic stem-cell transplantation in patients with multiple myeloma (BMT CTN 0102): a phase 3 biological assignment trial, Lancet Oncol. 12 (13) (2011) 1195-1203.

[71] J. El-Cheikh, R. Crocchiolo, S. Furst, A.M. Stoppa, P. Ladaique, C. Faucher, et al., Longterm outcome after allogeneic stem-cell transplantation with reduced-intensity conditioning in patients with multiple myeloma, Am. J. Hematol. 88 (5) (2013) 370-374.

[72] F. Garban, M. Attal, M. Michallet, C. Hulin, J.H. Bourhis, I. Yakoub-Agha, et al., Prospective comparison of autologous stem cell transplantation followed by dosereduced allograft (IFM99-03 trial) with tandem autologous stem cell transplantation (IFM99-04 trial) in high-risk de novo multiple myeloma, Blood 107 (9) (2006) 3474-3480.

[73] B. Bruno, M. Rotta, F. Patriarca, N. Mordini, B. Allione, F. Carnevale-Schianca, et al., A comparison of allografting with autografting for newly diagnosed myeloma, $\mathrm{N}$. Engl. J. Med. 356 (11) (2007) 1110-1120.

[74] L. Rosinol, J.A. Perez-Simon, A. Sureda, J. de la Rubia, F. de Arriba, J.J. Lahuerta, et al., A prospective PETHEMA study of tandem autologous transplantation versus autograft followed by reduced-intensity conditioning allogeneic transplantation in newly diagnosed multiple myeloma, Blood 112 (9) (2008) 3591-3593.

[75] B. Bjorkstrand, S. Iacobelli, U. Hegenbart, A. Gruber, H. Greinix, L. Volin, et al., Tandem autologous/reduced-intensity conditioning allogeneic stem-cell transplantation versus autologous transplantation in myeloma: long-term follow-up, J. Clin. Oncol. 29 (22) (2011) 3016-3022.

[76] B. Wirk, M. Byrne, Y. Dai, J.S. Moreb, Outcomes of salvage autologous versus allogeneic hematopoietic cell transplantation for relapsed multiple myeloma after initial autologous hematopoietic cell transplantation, J. Clin. Med. Res. 5 (3) (2013) 174-184.

[77] G. Gahrton, S. Iacobelli, B. Bjorkstrand, U. Hegenbart, A. Gruber, H. Greinix, et al., Autologous/reduced-intensity allogeneic stem cell transplantation vs autologous transplantation in multiple myeloma: long-term results of the EBMTNMAM2000 study, Blood 121 (25) (2013) 5055-5063.

[78] C.O. Freytes, D.H. Vesole, J. Lerademacher, X. Zhong, R.P. Gale, R.A. Kyle, et al., Second transplants for multiple myeloma relapsing after a previous autotransplantreduced-intensity allogeneic vs autologous transplantation, Bone Marrow Transplant. 49 (3) (2014) 416-421.

[79] E. Kneppers, B. van der Holt, M.J. Kersten, S. Zweegman, E. Meijer, G. Huls, et al., Lenalidomide maintenance after nonmyeloablative allogeneic stem cell transplantation in multiple myeloma is not feasible: results of the HOVON 76 Trial, Blood 118 (9) (2011) 2413-2419.

[80] M. Michallet, M. Sobh, J. El-Cheikh, S. Morisset, A. Sirvent, O. Reman, et al., Evolving strategies with immunomodulating drugs and tandem autologous/allogeneic hematopoietic stem cell transplantation in first line high risk multiple myeloma patients, Exp. Hematol. 41 (12) (2013) 1008-1015.

[81] M. Zeis, J. Steinmann, E. Petrela, G. Hartung, N. Schmitz, L. Uharek, Transfer of idiotypic protein primed allogeneic marrow grafts elicits potent graft-versus-myeloma effects in mice, Bone Marrow Transplant. 27 (3) (2001) 279-285.

[82] R. van der Voort, T.J. Volman, V. Verweij, P.C. Linssen, F. Maas, K.M. Hebeda, et al. Homing characteristics of donor $\mathrm{T}$ cells after experimental allogeneic bone marrow transplantation and posttransplantation therapy for multiple myeloma, Biol. Blood Marrow Transplant. 19 (3) (2013) 378-386. 
[83] H. Rozemuller, E. van der Spek, L.H. Bogers-Boer, M.C. Zwart, V. Verweij, M. Emmelot, et al., A bioluminescence imaging based in vivo model for preclinical testing of novel cellular immunotherapy strategies to improve the graft-versusmyeloma effect, Haematologica 93 (7) (2008) 1049-1057.

[84] L.M. Freeman, A. Lam, E. Petcu, R. Smith, A. Salajegheh, P. Diamond, et al., Myeloma-induced alloreactive T cells arising in myeloma-infiltrated bones include double-positive CD8+CD4 + T cells: evidence from myeloma-bearing mouse model, J. Immunol. 187 (8) (2011) 3987-3996.

[85] T. Guichelaar, M.E. Emmelot, H. Rozemuller, B. Martini, R.W. Groen, G. Storm, et al. Human regulatory $\mathrm{T}$ cells do not suppress the antitumor immunity in the bone marrow: a role for bone marrow stromal cells in neutralizing regulatory $\mathrm{T}$ cells, Clin. Cancer Res. 19 (6) (2013) 1467-1475.

[86] M. Hannon, C. Lechanteur, S. Lucas, J. Somja, L. Seidel, L. Belle, et al., Infusion of clinical-grade enriched regulatory $T$ cells delays experimental xenogeneic graftversus-host disease, Transfusion 54 (2) (2014) 353-363.

[87] A. Sharabi, N.H. Ghera, Breaking tolerance in a mouse model of multiple myeloma by chemoimmunotherapy, Adv. Cancer Res. 107 (2010) 1-37.

[88] A. Barber, K.R. Meehan, C.L. Sentman, Treatment of multiple myeloma with adoptively transferred chimeric NKG2D receptor-expressing T cells, Gene Ther. 18 (5) (2011) 509-516.

[89] G.F. Lauritzsen, S. Weiss, Z. Dembic, B. Bogen, Naive idiotype-specific CD4 + T cells and immunosurveillance of B-cell tumors, Proc. Natl. Acad. Sci. U. S. A. 91 (12) (1994) 5700-5704.

[90] H. Huang, F. Li, J.R. Gordon, J. Xiang, Synergistic enhancement of antitumor immunity with adoptively transferred tumor-specific CD4 + and CD8 + T cells and intratumoral lymphotactin transgene expression, Cancer Res. 62 (7) (2002) 2043-2051.

[91] H. Huang, Y. Liu, J. Xiang, Synergistic effect of adoptive T-cell therapy and intratumoral interferon gamma-inducible protein-10 transgene expression in treatment of established tumors, Cell. Immunol. 217 (1-2) (2002) 12-22.

[92] Y. Qi, T. Moyana, Y. Chen, J. Xiang, Characterization of anti-tumor immunity derived from the inoculation of myeloma cells secreting the fusion protein RM4 IFN-tau, Hum. Antibodies Hybridomas 7 (1) (1996) 21-26.

[93] J. Xiang, T. Moyana, Cytotoxic CD4 + T cells associated with the expression of major histocompatibility complex class II antigen of mouse myeloma cells secreting interferon-gamma are cytolytic in vitro and tumoricidal in vivo, Cancer Gene Ther. 5 (5) (1998) 313-320.

[94] J. Dou, Y. Wu, J. Wang, F. Zhao, L. Chu, C. Liu, et al., Eliciting protective immune responses against murine myeloma challenge in lymphopenia mice through adoptive transfer of tumor antigen-specific lymphocytes and immunization of tumor vaccine secreting mIL-21, Cancer Gene Ther. 17 (10) (2010) 675-683.

[95] M.A. Caligiuri, Human natural killer cells, Blood 112 (3) (2008) 461-469.

[96] E. Alici, K.V. Konstantinidis, T. Sutlu, A. Aints, G. Gahrton, H.-G. Ljunggren, et al. Anti-myeloma activity of endogenous and adoptively transferred activated natura killer cells in experimental multiple myeloma model, Exp. Hematol. 35 (12) (2007) 1839-1846.

[97] J. Shi, G. Tricot, S. Szmania, N. Rosen, T.K. Garg, P.A. Malaviarachchi, et al., Infusion of haplo-identical killer immunoglobulin-like receptor ligand mismatched NK cells for relapsed myeloma in the setting of autologous stem cell transplantation, Br. J. Haematol. 143 (5) (2008) 641-653.

[98] T.K. Garg, S.M. Szmania, J.A. Khan, A. Hoering, P.A. Malbrough, A. Moreno-Bost et al., Highly activated and expanded natural killer cells for multiple myeloma immunotherapy, Haematologica 97 (9) (2012) 1348-1356.

[99] D. Xing, A.G. Ramsay, J.G. Gribben, W.K. Decker, J.K. Burks, M. Munsell, et al., Cord blood natural killer cells exhibit impaired lytic immunological synapse formation that is reversed with IL-2 exvivo expansion, J. Immunother. 33 (7) (2010) 684-696

[100] N. Shah, B. Martin-Antonio, H. Yang S. Ku, D. A. Lee, LJ.N. Cooper, et al, Antigen presenting cell-mediated expansion of human umbilical cord blood yields logscale expansion of natural killer cells with anti-myeloma activity, PLoS ONE 8 (10) (2013) e76781

[101] F. Romagné, P. André, P. Spee, S. Zahn, N. Anfossi, L. Gauthier, et al., Preclinical characterization of 1-7F9, a novel human anti-KIR receptor therapeutic antibody that augments natural killer-mediated killing of tumor cells, Blood 114 (13) (2009) 2667-2677.

[102] D.M. Benson, C.E. Bakan, S. Zhang, S.M. Collins, J. Liang, S. Srivastava, et al., IPH2101, a novel anti-inhibitory KIR antibody, and lenalidomide combine to enhance the natural killer cell versus multiple myeloma effect, Blood 118 (24) (2011) 6387-6391.

[103] D.M. Benson, C.C. Hofmeister, S. Padmanabhan, A. Suvannasankha, S. Jagannath, R. Abonour, et al., A phase 1 trial of the anti-KIR antibody IPH2101 in patients with relapsed/refractory multiple myeloma, Blood 120 (22) (2012) 4324-4333.

[104] N. Korde, M. Carlsten, M.J. Lee, A. Minter, E. Tan, M. Kwok, et al., A phase II tria of pan-KIR2D blockade with IPH2101 in smoldering multiple myeloma, Haematologica 99 (6) (2014) e81-e83.

[105] M.V. Maus, C.H. June, Zoom zoom: racing CARs for multiple myeloma, Clin. Cancer Res. 19 (8) (2013) 1917-1919.

[106] M. Kalos, Carl H. June, Adoptive T cell transfer for cancer immunotherapy in the era of synthetic biology, Immunity 39 (1) (2013) 49-60

[107] J. Chu, Y. Deng, D.M. Benson, S. He, T. Hughes, J. Zhang, et al., CS1-specific chimeric antigen receptor (CAR)-engineered natural killer cells enhance in vitro and in vivo antitumor activity against human multiple myeloma, Leukemia 28 (4) (2013) 917-927.

[108] E.D. Hsi, R. Steinle, B. Balasa, S. Szmania, A. Draksharapu, B.P. Shum, et al., CS1, a potential new therapeutic antibody target for the treatment of multiple myeloma, Clin. Cancer Res. 14 (9) (2008) 2775-2784.

[109] D.M. Benson, J.C. Byrd, CS1-directed monoclonal antibody therapy for multiple myeloma, J. Clin. Oncol. 30 (16) (2012) 2013-2015.
[110] H. Jiang, W. Zhang, P. Shang, H. Zhang, W. Fu, F. Ye, et al., Transfection of chimeric anti-CD138 gene enhances natural killer cell activation and killing of multiple myeloma cells, Mol. Oncol. 8 (2) (2014) 297-310.

[111] J. Chu, S. He, Y. Deng, J. Zhang, Y. Peng, T. Hughes, et al., Genetic modification of T cells redirected towards CS1 enhances eradication of myeloma cells, Clin. Cancer Res. 20 (15) (2014) 3989-4000.

[112] K. Mihara, J. Bhattacharyya, A. Kitanaka, K. Yanagihara, T. Kubo, Y. Takei, et al., Tcell immunotherapy with a chimeric receptor against CD38 is effective in eliminating myeloma cells, Leukemia 26 (2) (2012) 365-367.

[113] CD56 targeted chimeric antigen receptors for immunotherapy of multiple myeloma, in: R. Benjamin, M. Condomines, G. Gunset, M. Sadelain (Eds.), Proceedings of the 103rd Annual Meeting of the American Association for Cancer Research, 2012, (Chicago, IL)

[114] A.J. Novak, J.R. Darce, B.K. Arendt, B. Harder, K. Henderson, W. Kindsvogel, et al., Expression of BCMA, TACI, and BAFF-R in multiple myeloma: a mechanism for growth and survival, Blood 103 (2) (2004) 689-694.

[115] R.O. Carpenter, M.O. Evbuomwan, S. Pittaluga, J.J. Rose, M. Raffeld, S. Yang, et al., Bcell maturation antigen is a promising target for adoptive T-cell therapy of multiple myeloma, Clin. Cancer Res. 19 (8) (2013) 2048-2060.

[116] S. Peinert, H.M. Prince, P.M. Guru, M.H. Kershaw, M.J. Smyth, J.A. Trapani, et al., Gene-modified T cells as immunotherapy for multiple myeloma and acute myeloid leukemia expressing the Lewis Y antigen, Gene Ther. 17 (5) (2010) 678-686.

[117] M. Casucci, B. Nicolis di Robilant, L. Falcone, B. Camisa, M. Norelli, P. Genovese, et al. , CD44v6-targeted T cells mediate potent antitumor effects against acute myeloid leukemia and multiple myeloma, Blood 122 (20) (2013) 3461-3472.

[118] A.L. Garfall, J.A. Fraietta, M.V. Maus, Immunotherapy with chimeric antigen receptors for multiple myeloma, Discov. Med. 17 (91) (2014) 37-46.

[119] T.N. Nguyen-Pham, Y.K. Lee, H.J. Kim, J.J. Lee, Immunotherapy using dendritic cells against multiple myeloma: how to improve? Clin. Dev. Immunol. 2012 (2012) 397648.

[120] B. Bogen, A mouse model for immunotherapy of myeloma, Hematol. J. 3 (5) (2002) 224-229.

[121] A. Corthay, K.U. Lundin, L.A. Munthe, M. Froyland, T. Gedde-Dahl, Z. Dembic, et al., Immunotherapy in multiple myeloma: Id-specific strategies suggested by studies in animal models, Cancer Immunol. Immunother. 53 (9) (2004) 759-769.

[122] R.G. Lynch, R.J. Graff, S. Sirisinha, E.S. Simms, H.N. Eisen, Myeloma proteins as tumorspecific transplantation antigens, Proc. Natl. Acad. Sci. U. S. A. 69 (6) (1972) 1540-1544.

[123] B. Bogen, B. Malissen, W. Haas, Idiotope-specific T cell clones that recognize syngeneic immunoglobulin fragments in the context of class II molecules, Eur. J. Immunol. 16 (11) (1986) 1373-1378.

[124] B. Bogen, J.D. Lambris, Minimum length of an idiotypic peptide and a model for its binding to a major histocompatibility complex class II molecule, EMBO J. 8 (7) (1989) 1947-1952.

[125] B. Bogen, L. Gleditsch, S. Weiss, Z. Dembic, Weak positive selection of transgenic T cell receptor-bearing thymocytes: importance of major histocompatibility complex class II, T cell receptor and CD4 surface molecule densities, Eur. J. Immunol. 22 (3) (1992) 703-709.

[126] A. Corthay, K.U. Lundin, K.B. Lorvik, P.O. Hofgaard, B. Bogen, Secretion of tumorspecific antigen by myeloma cells is required for cancer immunosurveillance by CD4 + T cells, Cancer Res. 69 (14) (2009) 5901-5907.

[127] A. Corthay, D.K. Skovseth, K.U. Lundin, E. Rosjo, H. Omholt, P.O. Hofgaard, et al., Primary antitumor immune response mediated by CD4 + T cells, Immunity 22 (3) (2005) 371-383.

[128] G.F. Lauritzsen, P.O. Hofgaard, K. Schenck, B. Bogen, Clonal deletion of thymocytes as a tumor escape mechanism, Int. J. Cancer 78 (2) (1998) 216-222.

[129] M. Zeis, H. Frenzke, N. Schmitz, L. Uharek, J. Steinmann, Idiotype protein-pulsed dendritic cells produce strong anti-myeloma effects after syngeneic stem cell transplantation in mice, Bone Marrow Transplant. 29 (3) (2002) 213-221.

[130] A.B. Fredriksen, I. Sandlie, B. Bogen, Targeted DNA vaccines for enhanced induction of idiotype-specific B and T cells, Front. Oncol. 2 (2012) 154.

[131] A.B. Fredriksen, I. Sandlie, B. Bogen, DNA vaccines increase immunogenicity of idiotypic tumor antigen by targeting novel fusion proteins to antigen-presenting cells, Mol. Ther. 13 (4) (2006) 776-785.

[132] M. Froyland, P.A. Ruffini, K.M. Thompson, T. Gedde-Dahl, A.B. Fredriksen, B. Bogen, Targeted idiotype-fusion DNA vaccines for human multiple myeloma: preclinical testing, Eur. J. Haematol. 86 (5) (2011) 385-395.

[133] K.W. Schjetne, A.B. Fredriksen, B. Bogen, Delivery of antigen to CD40 induces protective immune responses against tumors, J. Immunol. 178 (7) (2007) 4169-4176.

[134] A.B. Fredriksen, B. Bogen, Chemokine-idiotype fusion DNA vaccines are potentiated by bivalency and xenogeneic sequences, Blood 110 (6) (2007) 1797-1805.

[135] J. Qian, Y. Zheng, C. Zheng, L. Wang, H. Qin, S. Hong, et al., Active vaccination with Dickkopf-1 induces protective and therapeutic antitumor immunity in murine multiple myeloma, Blood 119 (1) (2012) 161-169.

[136] W.H. Hallett, W. Jing, W.R. Drobyski, B.D. Johnson, Immunosuppressive effects of multiple myeloma are overcome by PD-L1 blockade, Biol. Blood Marrow Transplant. 17 (8) (2011) 1133-1145.

[137] S. Cohen, J. Haimovich, N. Hollander, Dendritic cell-based therapeutic vaccination against myeloma: vaccine formulation determines efficacy against light chain myeloma, J. Immunol. 182 (3) (2009) 1667-1673.

[138] S. Hong, H. Li, J. Qian, J. Yang, Y. Lu, Q. Yi, Optimizing dendritic cell vaccine for immunotherapy in multiple myeloma: tumour lysates are more potent tumour antigens than idiotype protein to promote anti-tumour immunity, Clin. Exp. Immunol. 170 (2) (2012) 167-177.

[139] Y. Liu, W. Zhang, T. Chan, A. Saxena, J. Xiang, Engineered fusion hybrid vaccine of IL-4 gene-modified myeloma and relative mature dendritic cells enhances antitumor immunity, Leuk. Res. 26 (8) (2002) 757-763. 
[140] S. Hao, X. Bi, S. Xu, Y. Wei, X. Wu, X. Guo, et al., Enhanced antitumor immunity derived from a novel vaccine of fusion hybrid between dendritic and engineered myeloma cells, Exp. Oncol. 26 (4) (2004) 300-306.

[141] S. Wang, S. Hong, M. Wezeman, J. Qian, J. Yang, Q. Yi, Dendritic cell vaccine but not idiotype-KLH protein vaccine primes therapeutic tumor-specific immunity against multiple myeloma, Front. Biosci. 12 (2007) 3566-3575.

[142] A. Curti, P. Tosi, P. Comoli, C. Terragna, E. Ferri, C. Cellini, et al., Phase I/II clinical trial of sequential subcutaneous and intravenous delivery of dendritic cell vaccination for refractory multiple myeloma using patient-specific tumour idiotype protein or idiotype (VDJ)-derived class I-restricted peptides, Br. J. Haematol. 139 (3) (2007) 415-424.

[143] L. Zahradova, K. Mollova, D. Ocadlikova, L. Kovarova, Z. Adam, M. Krejci, et al., Efficacy and safety of Id-protein-loaded dendritic cell vaccine in patients with multiple myeloma-phase II study results, Neoplasma 59 (4) (2012) 440-449.

[144] J. Rosenblatt, I. Avivi, B. Vasir, L. Uhl, N.C. Munshi, T. Katz, et al., Vaccination with dendritic cell/tumor fusions following autologous stem cell transplant induces immunologic and clinical responses in multiple myeloma patients, Clin. Cancer Res. 19 (13) (2013) 3640-3648.

[145] P.O. Hofgaard, H.C. Jodal, K. Bommert, B. Huard, J. Caers, H. Carlsen, et al., A novel mouse model for multiple myeloma (MOPC315.BM) that allows noninvasive spatiotemporal detection of osteolytic disease, PLoS One 7 (12) (2012) e51892.
[146] H. McCarthy, C.H. Ottensmeier, T.J. Hamblin, F.K. Stevenson, Anti-idiotype vaccines, Br. J. Haematol. 123 (5) (2003) 770-781.

[147] R. Houot, R. Levy, Vaccines for lymphomas: idiotype vaccines and beyond, Blood Rev. 23 (3) (2009) 137-142.

[148] V.L. Reichardt, C.Y. Okada, A. Liso, C.J. Benike, K.E. Stockerl-Goldstein, E.G. Engleman, et al., Idiotype vaccination using dendritic cells after autologous peripheral blood stem cell transplantation for multiple myeloma-a feasibility study, Blood 93 (7) (1999) 2411-2419.

[149] N. Morito, K. Yoh, A. Maeda, T. Nakano, A. Fujita, M. Kusakabe, et al., A novel transgenic mouse model of the human multiple myeloma chromosomal translocation $\mathrm{t}(14 ; 16)$ (q32; q23), Cancer Res. 71 (2) (2011) 339-348.

[150] D.R. Carrasco, K. Sukhdeo, M. Protopopova, R. Sinha, M. Enos, D.E. Carrasco, et al., The differentiation and stress response factor XBP-1 drives multiple myeloma pathogenesis, Cancer Cell 11 (4) (2007) 349-360.

[151] M. Chesi, D.F. Robbiani, M. Sebag. W.J. Chng M. Affer, R. Tiedemann, et al., AIDdependent activation of a MYC transgene induces multiple myeloma in a conditional mouse model of post-germinal center malignancies, Cancer Cell 13 (2) (2008) 167-180.

[152] J. Vera, B. Savoldo, S. Vigouroux, E. Biagi, M. Pule, C. Rossig, et al., T lymphocytes redirected against the kappa light chain of human immunoglobulin efficiently kill mature B lymphocyte-derived malignant cells, Blood 108 (12) (2006) 3890-3897. 